\title{
EchoGéo
}

$44 \mid 2018$

Les valorisations territoriales et touristiques du street art

\section{Le street art, outil de valorisation territoriale et touristique : l'exemple de la Galeria de Arte Urbana de Lisbonne}

\section{Alexandre Grondeau and Florence Pondaven}

\section{OpenEdition}

\section{Journals}

Electronic version

URL: https://journals.openedition.org/echogeo/15324

DOI: 10.4000/echogeo.15324

ISSN: 1963-1197

Publisher

Pôle de recherche pour l'organisation et la diffusion de l'information géographique (CNRS UMR 8586)

Electronic reference

Alexandre Grondeau and Florence Pondaven, "Le street art, outil de valorisation territoriale et touristique : l'exemple de la Galeria de Arte Urbana de Lisbonne", EchoGéo [Online], 44 | 2018, Online since 31 July 2018, connection on 31 July 2021. URL: http://journals.openedition.org/echogeo/15324 ; DOI: https://doi.org/10.4000/echogeo.15324

This text was automatically generated on 31 July 2021

EchoGéo est mis à disposition selon les termes de la licence Creative Commons Attribution - Pas d'Utilisation Commerciale - Pas de Modification 4.0 International (CC BY-NC-ND) 


\section{Le street art, outil de valorisation} territoriale et touristique : l'exemple de la Galeria de Arte Urbana de Lisbonne

Alexandre Grondeau and Florence Pondaven

Illustration 1 - Fresque Maryline de la Galeria de Arte Urbana

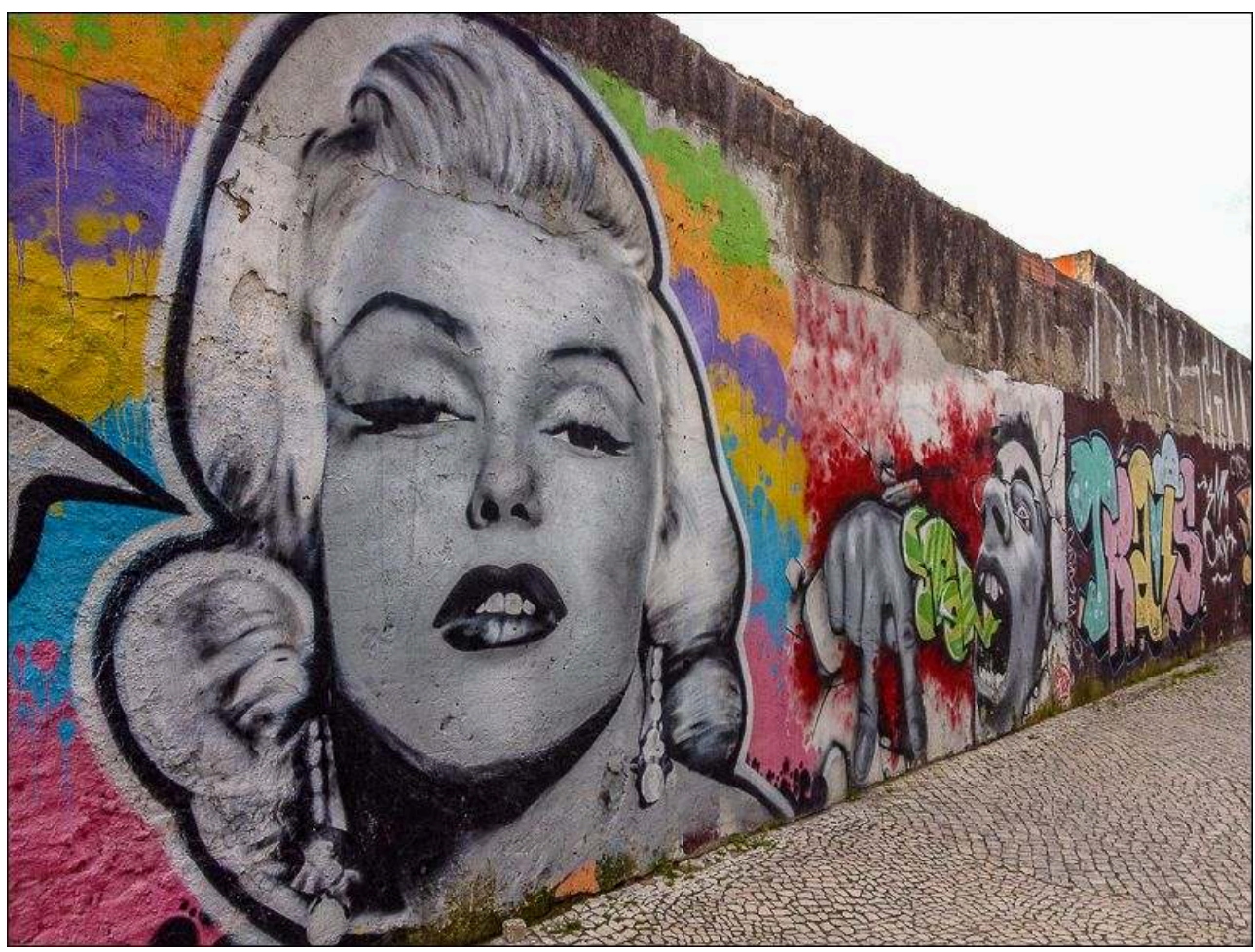

Auteur : A. Grondeau, février 2015. 
1 Longtemps identifié comme un art de rue vandale et illégal parasitant la ville (Wilson \& Kelling, 1982 ; Keizer, Lindenberg \& Steg, 2008 ; Thompson et al., 2012), le street art (SA) est devenu un solide outil au service des politiques urbaines et culturelles des métropoles occidentales, en particulier dans les opérations de régénération urbaine (Morovich, 2014 ; Landes, 2015) et la définition des stratégies de marketing territorial (Droney, 2010 ; Borghini, Visconti, Anderson \& Sherry, 2010 ; McAuliffe, 2012 ; Genin, 2015). Depuis trente ans en effet, dans un contexte de concurrence entre les territoires exacerbée par le processus de mondialisation, les métropoles ont eu l'obligation de se différencier pour attirer un maximum d'investissements, de touristes ou de créatifs (Storm, 2003). Elles sont devenues ludiques (Burgel, 1999; Burgel \& Grondeau, 2015). Leur niveau d'attractivité s'est mis à dépendre plus fortement de la qualité et de la singularité des lieux à l'instar de Melbourne (Young, 2010), Berlin (Irvine, 2012), Londres (Dickens, 2010), Miami (Ferrell, 2016) qui ont su intégrer le street art dans leur stratégie de développement urbain et d'amélioration de leur cadre de vie.

2 C'est dans ce contexte que la fabrique de la ville par la culture est passée par le réinvestissement des espaces publics via des projets d'art in situ. L'art est alors envisagé comme un moyen de redonner sa dimension sociale et symbolique aux espaces publics (Ghorra-Gobin, 2009; Guinard, 2010) autant que comme un moyen de créer une ambiance urbaine, agréable pour les habitants et attractive pour les touristes (Rousseau, 2008). Les arts de la marge deviennent alors des arts reconnus grâce au processus d'artification (Heinich \& Shapiro, 2012). Le street art en est un très bon exemple puisqu'il est passé d'une pratique criminalisée (Austin, 2001; McAuliffe \& Iveson, 2011) à une pratique valorisée et institutionnalisée (Baudrillard \& Lotringer, 2005 ; Halsey \& Young, 2006 ; Halsey \& Pederick, 2010).

3 Nous entendons le street art dans son acception "protéiforme et évolutive » (Genin, 2013), appréhendé comme une forme d'art urbain, légal ou illégal, pratiquée de manière éphémère sur différents types de supports appartenant à l'espace public. Il englobe de ce point de vue la notion de graffiti, au sens de McAuliffe (2012): une pratique provenant de la contre-culture hip-hop, s'appropriant l'espace public de manière illégale et caractérisée visuellement par le writing. Il inclut également les pratiques politiques (Baudrillard et al., 1974 ; Fraenkel, 2007), identitaires (Penn, 2005 ; Ginhoux, 2015) de la fresque ou de l'écriture murale. Le street art se présente ainsi comme un moyen d'expression alternatif qui va être progressivement intégré aux politiques et aux stratégies de valorisation territoriale et de développement des grandes métropoles comme ce fut le cas à Lisbonne à partir de la mise en place de la Galeria de Arte Urbana (GAU) à la fin des années 2000.

4 La pratique artistique en espace public au Portugal est ancienne. L'art de la calçada date du XIX' siècle (Bairrada, Monteiro, Cabral \& dos Santos, 1985 ; Yazigi, 1996) et celui des azulejos est apparu sur les façades extérieures au XVIII ${ }^{\mathrm{e}}$ siècle (de Araújo \& de Jesus Martins, 1938 ; Santana \& Sucena, 1994). Ils peuvent tous deux être envisagés comme des ancêtres du street art local, mais dans cette recherche, nous nous concentrerons sur l'étude du street art lisboète contemporain et sa capacité à participer à la promotion urbaine de la métropole et à l'intégration sociale de populations en marge. Nous considérons donc que le street art lisboète contemporain débute avec sa pratique vandale au milieu des années 1970 et la lutte politique contre la dictature de Salazar (Cruzeiro, 2004; Campos, 2009 ; Saldanha, 2013). Il s'incarne ensuite dans la réalisation toujours illégale de graffiti hip-hop dans les périphéries de la métropole, à Cascais, 
Carcavelos et Estoril, villes balnéaires à côté de Lisbonne (Moore \& Cruz, 2007 ; M. Moore, 2010); dans les quartiers périphériques lisboètes Alcantara, Amadora, Oeiras ; avant de se localiser dans le centre historique dans les années 1990, à une époque où le quartier devient créatif le jour (Costa, 2013) et festif la nuit (Almeida, Fumega \& Alves, 2011). On retrouve alors le street art lisboète sur les murs délabrés des espaces en marge, des quartiers en friches, les murs du métro dans la tradition des murales et du graffiti writing nord-américain avant que la ville de Lisbonne ne décide de l'aménagement de la Galeria de Arte Urbana (Gabriel, Estevens \& André, 2013 ; Campos, 2014) et ne bouleverse la géographie du street art local. Le projet de Galeria de Arte Urbana est ainsi inscrit au sein de la politique culturelle et urbaine de la municipalité depuis 2008.

5 L'objectif de cet article est d'analyser l'expérience de la Galeria de Arte Urbana à travers le prisme du street art lisboète contemporain envisagé comme un outil institutionnel au service de la valorisation territoriale et touristique. Nous avons donc identifié les trois formes graphiques de la pratique picturale et scripturale que l'on retrouve sur les murs de Lisbonne au sein de la Galeria de Arte Urbana et nous les avons dénommées "street art iconique ", "graffiti hip-hop » et "street art politique ». Le street art iconique concerne les fresques qui sont majoritairement constituées de formes et de références iconiques, avec assez peu de lettrages, et dont le sens est accessible à la plus large audience. Le graffiti hip-hop regroupe, lui, les formes de lettrage qui véhiculent l'esthétique et les codes de la contre-culture graffiti liés au mouvement hiphop. Le graffiti politique recense tous les types de positionnement politique (critique du capitalisme, dénonciation de la situation en Palestine, revendications féministes ou antiracistes...) mis en avant par les artistes au sein des fresques de la Galeria de Arte Urbana. Ces trois catégories concernent également l'ensemble du mouvement street art lisboète, qui les réalise par ailleurs de façon vandale (illégale). Cependant, dans la mesure où notre recherche s'attache à évaluer les impacts territoriaux et sociaux de la Galeria de Arte Urbana, et leurs limites, nous nous concentrerons sur les fresques réalisées par des artistes dans son périmètre.

6 Pour ce faire, nous avons réalisé une étude de terrain de sept mois, de février à août 2015, et différentes missions qui ont permis d'établir une typologie des différents auteurs, modes, supports et sens du street art existant dans la Galeria de Arte Urbana ainsi que sa géolocalisation dans la métropole. Nous avons comparé cette cartographie du street art institutionnel au contexte culturel, créatif et sociologique métropolitain et pratiqué une quarantaine d'entretiens semi-directifs, formels et informels (avec une majorité d'entretiens informels en raison du caractère underground et subversif de la pratique de certains street artistes) avec des acteurs et des opposants de la Galeria de Arte Urbana afin de mettre en perspectives notre analyse. Nous avons enfin analysé la manière dont la Galeria de Arte Urbana était traitée dans le quotidien portugais Publico, très lu à Lisbonne, afin de mesurer le rayonnement local du projet et les débats qui traversent les lisboètes. Une analyse a également été réalisée dans la presse internationale afin d'évaluer le rayonnement médiatique international.

\section{Aux origines de la Galeria de Arte Urbana : culture, créativité et gentrification lisboètes}


Illustrations 2 et 3 - Fresques de la Galeria de Arte Urbana
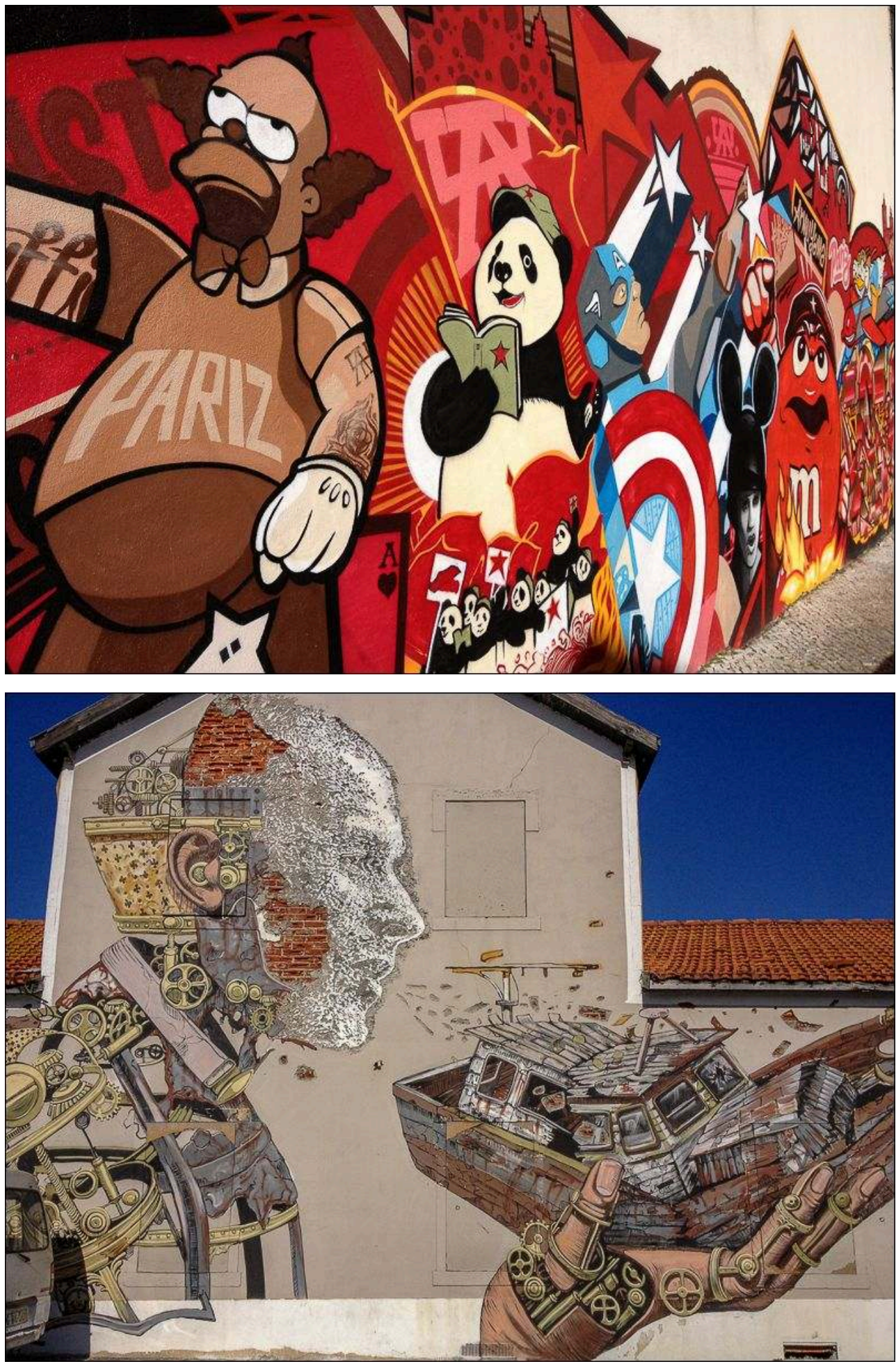

Auteur : A. Grondeau, février 2015.

7 Le Street Art portugais contemporain trouve son origine dans la pratique des « muraux politiques" notamment pendant la Révolution des Cillets qui mit un terme à la dictature salazariste. Il s'est ensuite développé à la fin des années 1980, dans la périphérie de la métropole lisboète, influencé notamment par l'introduction de la culture hip-hop depuis les États-Unis et les grandes capitales européennes (Costa \& 
Lopes, 2015). Ainsi, en 1986, est organisé le premier concours de graffiti à Oeiras, un district de la municipalité lisboète. La diffusion du street art portugais va alors s'opérer dans le temps de la périphérie vers le centre historique ${ }^{1}$ puis vers les autres villes portugaises (Gabriel et al., 2013).

8 À cette époque, et malgré quelques rares initiatives de vulgarisation, la pratique du street art est totalement illégale et combattue par les pouvoirs publics. La municipalité dirigée par Jorge Sampaio, socialiste qui a quitté la municipalité de Lisbonne pour devenir président du Portugal en 1996, suit de ce point de vue les politiques des grandes métropoles mondiales touchées par le phénomène, en s'inspirant de la politique new yorkaise de tolérance zéro (Ferrell, 1993 ; Dickinson, 2008). C'est dans les années 1990 que la place de la culture évolue dans les politiques municipales. Jorge Sampaio, puis João Soares qui le remplace en 1996, décident de se servir de la culture et des grandes manifestations internationales pour transformer la capitale du Portugal. La ville de Lisbonne est ainsi élue capitale européenne de la culture en 1994. L'événement amorce la transformation de la métropole et entérine l'acte d'intégration du Portugal huit ans plus tôt dans la CEE (Communauté économique européenne, 1986; Holton, 1998). Lisbonne célèbre ensuite le $500^{\mathrm{e}}$ anniversaire de la découverte de la route des Indes de Vasco de Gama avec l'Expo' 98 « Os Oceanios um Património para o Futuro ». Le site de l'exposition se situe sur la rive orientale du front du Tage, dans la freguesia actuelle du Parque das Nações qui a été complètement réhabilitée, réaménagée et dépolluée afin de devenir une nouvelle centralité de Lisbonne, suivant les recommandations du plan de réhabilitation PUZI (O Plano de urbanização da zona de intervenção da Expo 98) (Rosa, 1999) validé en 1994. Ce réaménagement passe par la construction de logements, l'installation d'infrastructures structurantes, commerciales et routières, et la délocalisation d'industries polluantes (Castro, Lucas, Ferreira et al., 1997 ; Ferreira, 2010). C'est à cette époque également que la municipalité change de stratégie de développement en mettant notamment en place une politique mixte « de développement urbain alternative » où les activités créatives et culturelles jouent un rôle déterminant (Costa \& Lopes, 2015).

Des festivals et des évènements collectifs sont organisés par la société civile, avec l'autorisation de la municipalité, comme la " $1^{\text {ère }}$ rencontre internationale de graffiti » qui se déroule à Oeiras en 1999. Cependant, la pratique vandale de cet art de rue continue à être réprimée par la municipalité, en particulier dans le centre historique lisboète dont la dimension culturelle est identifiée comme un vecteur important d'attractivité (M. Moore, 2010; Simões, 2014). Dès la fin des années 1970, le centre historique a bénéficié d'un classement de la Baixa Chiado comme patrimoine culturel de la ville (Lopes \& Catarino, 2013), puis il a vu progressivement le reste des quartiers $\mathrm{du}$ centre historique reconnu espaces patrimoniaux (Camarinhas, 2006). Ce processus de patrimonialisation a suivi les préconisations de l'UNESCO de 1972 (Cousin, 2008) qui ont notamment été intégrées dans les documents stratégiques municipaux : «Lisbonne 2012, Visions stratégiques » (CML, 2005) et le Plan Stratégique de Lisbonne en 1992 (CML, 1992). Cette patrimonialisation a été motivée autant par la nécessité de restauration du bâti que par la volonté de faire du centre historique de Lisbonne un centre attractif pour les touristes et les investissements. Le projet de développement touristique du centre historique de Lisbonne a été accompagné d'un certain nombre de mesures visant à maintenir les populations défavorisées via des aides financières, même si cette stratégie n'a pas pu véritablement enrayer le phénomène de 
gentrification du quartier, et les conflits sociaux entre les habitants et la municipalité (Galhardo, 2014 ; Observatório do QREN, 2013).

Illustration 4 - Le centre historique de Lisbonne et ses différents quartiers (1/33 000)

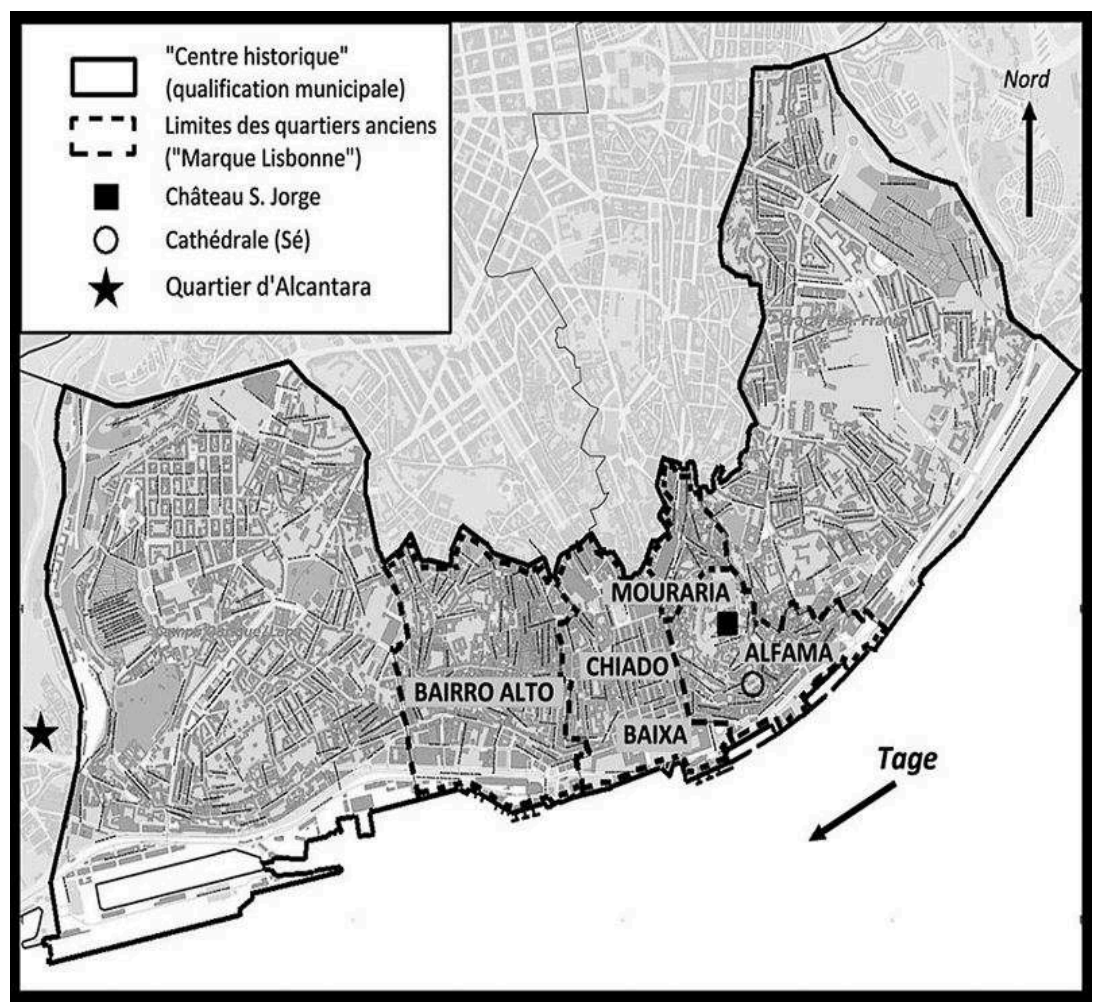

Le début des années 2000 va accélérer le rapprochement et le renforcement de la culture, des industries créatives et du street art dans l'offre de développement local lisboète. Ainsi, le document directeur «Vision stratégique, Lisbonne 2012 » se positionne en faveur de la culture comme levier de développement urbain à Lisbonne, à travers les activités créatives et culturelles, l'innovation et la valorisation des lieux de culture (CML, 2005 ; Carrancal, 2009). Conscients des grands enjeux soulevés par le Traité de Lisbonne (Union Européenne, 2007), les maires qui se succèdent à la tête de la municipalité favorisent la modernisation de la ville autour des activités innovantes et créatives et permettent à Lisbonne d'arriver en troisième position (derrière Amsterdam et Copenhague) du rapport « The Cultural and Creative Cities Monitor » produit par le bureau national du tourisme (Saisana, Montalto, Orge Tacao Moura \& Langedijk, 2017). Le mandat d'Antonio Costa a été décisif dans ce tournant économique qui a notamment permis à la ville d'héberger le festival «Eurobest-Festival of European creativity » qui célèbre les villes créatives, en 2011, 2012, 2013 à Lisbonne. La réussite créative lisboète s'illustre également à travers la mise en place de politiques et des aménagements favorables comme Fablab Lisboa (Gaeiras, 2017), Startup Lisboa (2011, http:// www.startuplisboa.com/) et la LX Factory (http://www.lxfactory.com), la friche culturelle emblématique de la ville intégrée au plan d'urbanisme Alcantara XXI en 2005 (Costa, 2007; Gravereau, 2012). L'ancienne usine de filage et de textile est devenue, grâce à l'action conjointe de la société immobilière Main Side propriétaire des lieux et de la municipalité lisboète, un centre artistique et culturel consacré aux loisirs et à la créativité (Gravereau, 2012 ; CML, 2013) avec plusieurs fresques murales sur ses façades (Dourado Sequeira, 2015). L'idée était de créer une nouvelle centralité en mettant en 
avant l'aspect industriel du patrimoine lisboète, et sa reconversion culturelle et créative dans lequel le street art joue un rôle de marqueur d'image important (Giroud, 2007 ; Cabeçadas Do Carmo, Pattaroni, Pedrazzini \& Piraud, 2014).

11 Dans ces perspectives créatives et culturelles, l'art de rue institutionnalisé est envisagé dans sa capacité à créer une ambiance urbaine particulière, artistique, qui attirera les créatifs de ces territoires (Rousseau, 2008). Les activités de la Galeria de Arte Urbana à Lisbonne, considérée par leur directrice Sylvia Câmara comme « un modèle alternatif d'équipement culturel de la ville » (Câmara, 2013), sont perçues par la municipalité comme autant de dispositifs d'esthétisation de la culture alternative, permettant de créer un environnement reconnaissable et associé aux concepts de créativité urbaine (Cabeçadas Do Carmo et al., 2014). C'est la raison essentielle pour laquelle la municipalité a maintenu le street art dans et autour du Bairro Alto. Le street art crée une identité esthétique reconnaissable, donne au quartier des images et un décor spécifique pour les activités de tourisme et les activités créatives mises en place à partir des années 2010 dans le Bairro Alto. Il renforce ainsi l'image de cluster créatif souhaité par la municipalité (Cinti, 2008 ; Marques, 2017) et participe au processus de gentrification qu'on y observe.

Les politiques culturelles et créatives, la concentration des lieux festifs et la patrimonialisation du centre historique lisboète se sont en effet accompagnées de sa gentrification partielle. Selon l'observatório das Desigualdades ${ }^{2}$, la gentrification a touché plus fortement les quartiers à vocation touristique et créative du Bairro Alto, de l'Alfama, et du Baixa Chiado que le quartier multiculturel de la Mouraria (Fortuna \& Peixoto, 2005 ; Giroud, 2007 ; Menezes, 2011 ; Galhardo, 2014). Dans tous les cas, elle a provoqué des réactions, des résistances, des luttes qui se sont exprimées sur les murs de ces quartiers de manière vandale et légale (da Costa Xavier \& de Almeida, 2017). Légalement avec la mise en place d'ateliers participatifs pour sensibiliser la population au street art, et la réalisation de fresques sur le mur de clôture Rua Adriano Correia de Oliveira dans la freguesia Nova. Illégalement, avec les street artistes vandales qui ont dénoncé la disneylandisation du centre historique, la disparation des commerces de bouche dans le Bairro Alto et la recrudescence des logements Airbnb et des hôtels (Costa, 2013 ; Pavel, 2016). De fait, les conflits d'usages entre résidents mécontents des nuisances sonores liées aux activités nocturnes du Bairro Alto et les mécontents des graffitis vandales sur les façades ont obligé la municipalité à prendre deux types de mesures pour contrôler le graffiti, notamment dans le quartier du Bairro Alto: des mesures répressives (kit de nettoyage distribué aux habitants, test de peinture anti graffiti, surveillance), mais également des mesures innovantes «inclusives» et " compréhensives" qui proposent aux artistes des espaces institutionnels où peindre (Costa, 2013). C'est dans ce contexte que la Galeria de Arte Urbana a été mise en place à la fin des années 2000.

\section{La GAU : portrait, fonctionnement et objectifs}

13 La Galeria de Arte Urbana a vu le jour en 2008, à l'occasion d'un programme de réhabilitation des quartiers anciens du Bairro Alto et de la Baixa Chiado. Ce programme fut initié par la municipalité afin de sécuriser le quartier et d'améliorer sa qualité de vie. Le maire de l'époque, Antonio Costa, précisait alors sa vision du street art local : « ce sont sur ces deux registres que nous devons agir: un espace légal pour la liberté de 
création, et en même temps nous prenons des mesures vis à vis des peintures faites « illégalement » ( (publico.pt, 2008). Le premier projet de la GAU a été le projet CRONO, mené en centre-ville où des grands immeubles abandonnés ont été peints à chaque saison pendant un an par des artistes internationaux comme Blu et Os Gemeos. Il a valu à Lisbonne d'être classé dans les «top ten best street art work in the world» en 2014 par le Guardian (Neves, 2011). D'autres projets ont suivi comme les panneaux à peindre disposés dans la Calçada de Gloria, entrée du quartier du Bairro Alto, ou la mise à disposition, après sélection, de containers de recyclage et de camions poubelles fournis par la municipalité aux street artistes afin qu'ils peignent dessus (Campos, 2009; Costa \& Lopes, 2015).

Depuis sa création, la Galeria de Arte Urbana fait partie du département du patrimoine culturel de la ville de Lisbonne et compte plus de 150 fresques. Sa codirectrice Inês Machado l'a défini ainsi : « La Galeria de Arte Urbana représente la stratégie municipale concernant l'art urbain à Lisbonne. Cette stratégie consiste en la promotion, et au développement de l'importance du graffiti et du street art au sein de la scène artistique lisboète. La Galeria de Arte Uubana croit en une coexistence de tous les langages artistiques au sein du paysage urbain, en suivant une démarche démocratique, tout en ayant à l'esprit l'importance de la préservation du patrimoine culturel, de sa conservation et de sa restauration" (entretien semi-directif réalisé le 15/06/15, Lisbonne). La Galeria de Arte Urbana apparaît donc comme une composante importante de la politique culturelle métropolitaine : sa gestion est intégrée au département du Patrimoine Culturel de Lisbonne, inscrit lui-même au sein du budget culturel de la ville. Le financement de la Galeria de Arte Urbana est mixte depuis son origine. Il provenait, à l'époque, pour $80 \%$ de financements publics et le reste relevait du secteur privé. Aujourd'hui, la Galeria de Arte Urbana se présente comme un facilitateur des pratiques artistiques des personnes souhaitant peindre dans la rue de façon légale. Elle a permis et encouragé, depuis sa création, plus de quatre cents interventions artistiques réalisées par près de trois cent artistes de trente nationalités différentes. Pour intégrer la Galeria de Arte Urbana, les artistes doivent envoyer des propositions de fresques, stipulant l'endroit précis où ils souhaiteraient les réaliser et le prototype de leurs fresques. Ces propositions sont ensuite étudiées par l'équipe de la Galeria de Arte Urbana qui a en charge la direction artistique du projet et fait son choix en fonction de sa qualité plastique, de son thème.

Une fois l'œuvre choisie, la Galeria de Arte Urbana rentre en contact avec la direction générale du territoire, l'unité d'intervention territoriale, le département du patrimoine et de la réhabilitation urbaine qui, ensemble, se concertent et vérifient que le mur souhaité n'est pas classé au patrimoine urbain historique de la ville. À la suite de cette première étude, ils acceptent ou rejettent la demande. Dans le cas où le bâtiment appartient à un individu privé et non à la municipalité, il revient à l'artiste lui-même de convaincre le propriétaire de son projet.

\section{Caractéristiques et typologie du street art de la Galeria de Arte Urbana}

Pour mieux appréhender la Galeria de Arte Urbana, nous avons cartographié et caractérisé ses fresques en fonction de trois grandes caractéristiques du street art: les 
différents types de message véhiculés, les différents types de supports physiques sur lesquels les fresques sont apposées et les techniques utilisées par les artistes.

Concernant la première caractéristique, nous avons distingué et présenté plus haut les trois types d'interventions picturales et scripturales que l'on retrouve dans la Galeria de Arte Urbana : "street art iconique », "graffiti hip-hop » et «street art politique ». Cette distinction permet de mieux appréhender la géographie du street art lisboète institutionnalisé. Le street art iconique représente $70 \%$ des fresques en 2014 et $78 \%$ des fresques en 2016 ; le street art politique en représente $18 \%$ en 2014 contre $6 \%$ en 2016 ; le graffiti hip-hop correspond à $12 \%$ des fresques en 2014 et $15 \%$ en 2016. On remarque également en 2016 l'apparition de deux sculptures intégrées à l'espace public lisboète, présentées par la municipalité comme appartenant au projet de la Galeria de Arte Urbana. La répartition spatiale des fresques de type street art iconique, du fait de leur très grande majorité ( $78 \%$ ), épouse la répartition spatiale générale de la Galeria de Arte Urbana. On les retrouve localisées dans tout le périmètre de la galerie. Nous observons notamment une concentration de pièces de street art iconique dans le Bairro Alto, du fait du dispositif d'exposition créé par la Galeria de Arte Urbana dans la Calçada de Gloria et composé d'une dizaine de panneaux amovibles, peints cycliquement par des artistes. La Calçada da Gloria est une rue très empruntée par les touristes, à pied ou grâce à un ancien funiculaire qui permet de monter cette rue abrupte et de relier le quartier de Rossio au Bairro Alto. La répartition des fresques dans le reste de la ville, est structurée par le front de Tage à l'ouest de Lisbonne, le long duquel de nombreuses fresques sont alignées dans les freguesias d'Alcantara, Santos, Prazeres. Vers le Nord de la ville, les fresques sont réparties en suivant le dessin des axes de communication, autour des plus grosses voies routières. On remarque également une succession de fresques iconiques dans la freguesia d'Alvalade au Nord de Lisbonne, proche de l'aéroport, dont la concentration est due au projet «Os rostos do muro Azul » qui réunit des fresques iconiques, sur fond bleu, pour border l'enceinte de l'hôpital psychiatrique « Pavilhão 31 » (Dourado Sequeira, 2015).

18 Le type de fresque hip-hop se localise préférentiellement hors du centre-ville lisboète, à proximité des grands axes de communication d'où ils sont visibles, épousant ainsi les pratiques traditionnelles des street artistes hip-hop. Ces localisations sont parfaitement en lien avec le graffiti hip-hop et ses codes (Chang, 2007).

Les expressions politiques concernent quant à elles pour un tiers la lutte contre le capitalisme, et pour un quart dénoncent des tensions concernant la crise économique ou l'Union Européenne. Les messages questionnent également le rôle de l'art dans la société et le statut de la femme en mettant en avant des positionnements féministes. En 2016, on observe de nombreuses fresques réalisées en hommage à la Révolution des CEillets à l'occasion de l'anniversaire des quarante ans de la chute de la dictature (et de la fin de l'ère coloniale portugaise). Le street art politique se localise de manière indifférenciée dans la Galeria de Arte Urbana même si l'on observe une forte concentration de ce type près des universités. Bien que la Galeria de Arte Urbana soit institutionnalisée, l'expression d'opinions politiques est donc autorisée, mais l'on note l'absence de fresques en référence à la politique de la municipalité lisboète et aux personnages politiques locaux. 
Illustration 5 - Type de fresques de la Galeria de Arte Urbana en 2014

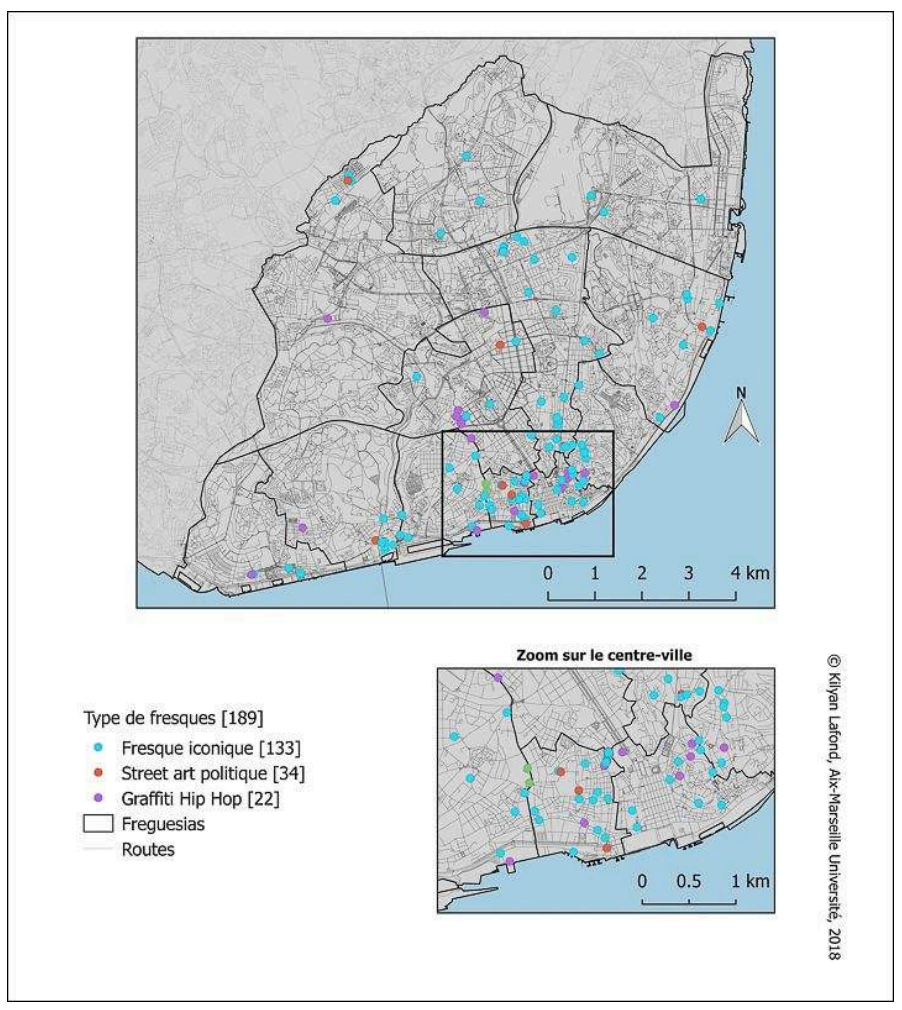

Illustration 6 - Type de fresques de la Galeria de Arte Urbana en 2016

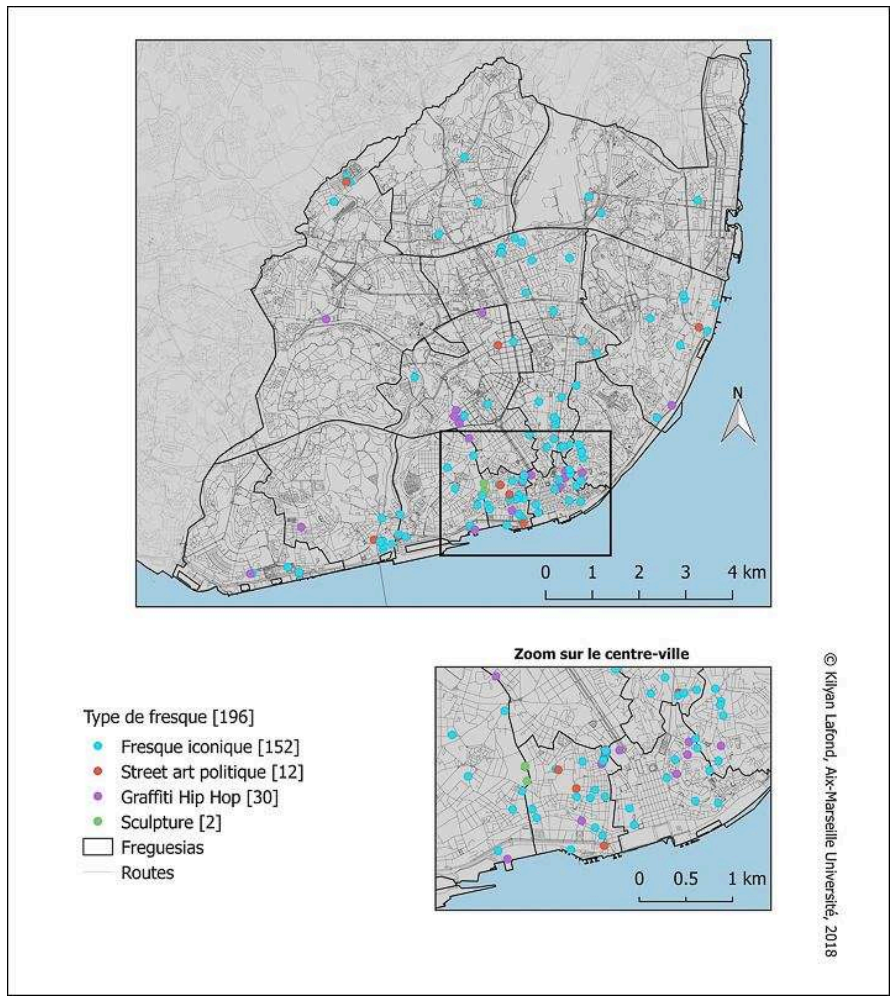

Le second élément de caractérisation de la Galeria de Arte Urbana est le type de support utilisé pour les fresques. Le support physique permet de mesurer l'empreinte 
urbaine de la Galeria de Arte Urbana. Notre recensement indique que le support physique utilisé est principalement le mur (67\% des fresques recensées en 2014, contre $69 \%$ en 2016) même si les containers de recyclage (11\%) et le mobilier urbain (7 \% en 2014 contre $9,69 \%$ en 2016) constituent des supports remarquables. Ces derniers correspondent en effet au projet « Recicle o olhar » mis en place en 2011 afin de rendre attractives les pratiques écologiques urbaines. Le reste des supports physiques consacrés aux fresques de la Galeria de Arte Urbana correspond à la mise en place de panneaux en bois concentrés dans le centre historique, majoritairement dans la Calçada da Gloria, qui en 2016 représentaient $18 \%$ des supports et le sol. Nous avons également caractérisé ce support physique de l'œuvre en fonction de la classification établie par l'institut statistique portugais ${ }^{3}$ : bon état (le mur ne présente pas de fissure, trou ou grosse écaille de peinture...), mauvais état (le mur présente des fissures, trous, grosses écailles de peinture...) et bâtiment abandonné (les fenêtres et/ou portes sont murées, les fenêtres n'ont plus de vitres, les portes sont cassées...). Ainsi, les murs considérés en bon état représentent $68 \%$ des murs de la Galeria de Arte Urbana, les fresques situées sur des murs en mauvais état en représentent $16 \%$ et $16 \%$ des fresques ont été réalisées sur des murs appartenant à des bâtiments abandonnés. Une logique spatiale assez nette concernant l'état des murs représentés se dégage. Les fresques du centre historique sont souvent réalisées sur des murs en bon état. Cela s'explique par la volonté de la municipalité lisboète de valoriser le centre d'un point de vue touristique et de structurer un cluster créatif au Bairro Alto. De ce point de vue, le street art institutionnalisé lisboète permet la définition d'une identité esthétique reconnaissable qui correspond à la manière dont la mairie veut positionner et promouvoir son centre historique en termes d'images : entre modernité, créativité, patrimoine et originalité. Les murs en mauvais état sont, eux, majoritairement situés en périphérie, où la fonction urbaine principale est résidentielle. Cependant, cette logique doit être nuancée car certaines fresques ont été volontairement installées sur des bâtiments vacants de la ville dont la façade était dégradée comme dans le cas du projet CRONO décrit plus haut. 
Illustration 7 - État du support des fresques de la Galeria de Arte Urbana en 2014

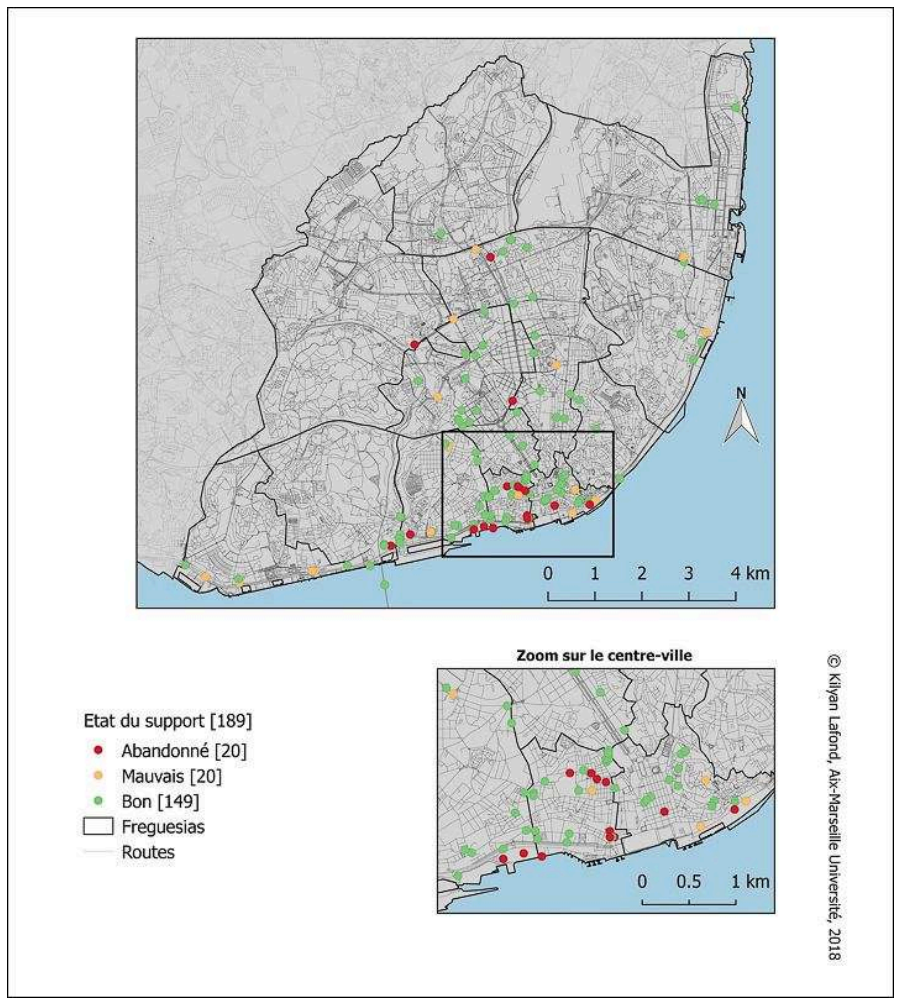

Illustration 8 - État du support des fresques de la Galeria de Arte Urbana en 2016

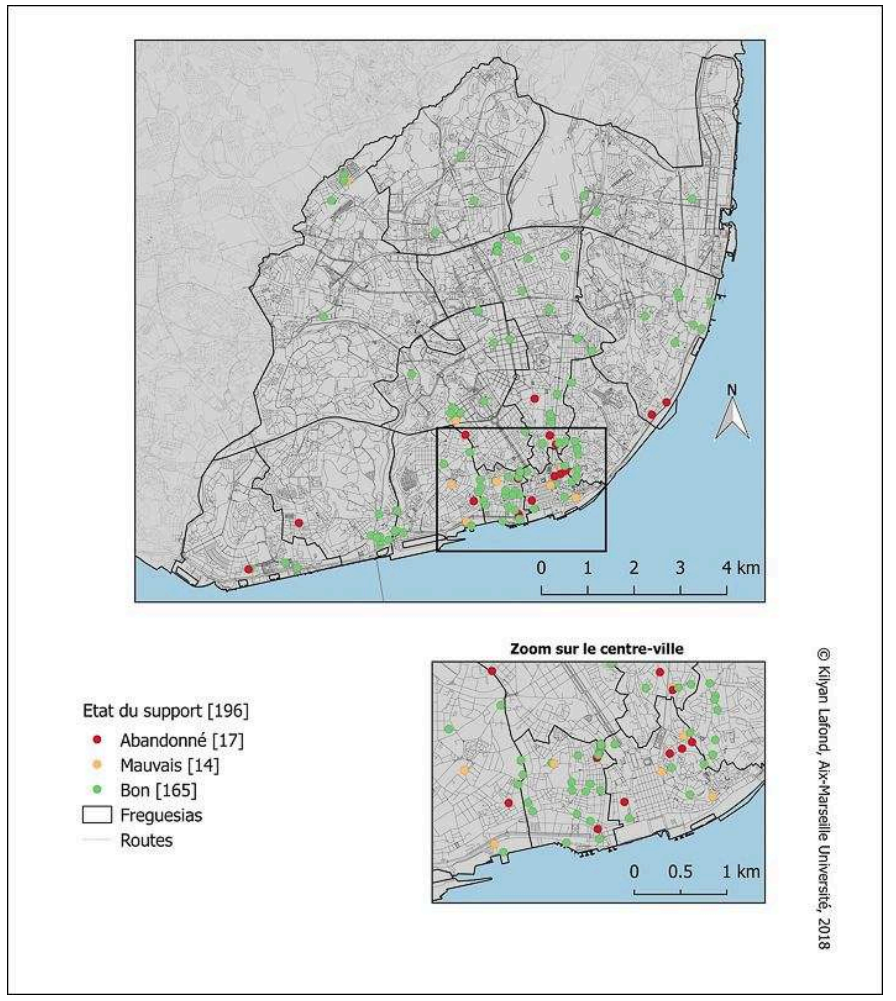

21 Le troisième élément de caractérisation du street art est la technique employée pour les réaliser. La peinture à la bombe ou au rouleau représente une importante majorité de 
fresques ( $75 \%$ en 2014 , contre $85 \%$ en 2016), puis vient le pochoir ( $15 \%$ en 2014 contre $6 \%$ en 2016), le collage/affichage ( $8 \%$ en 2014 contre $6 \%$ en 2016). Dans une moindre mesure des fresques sont également effectuées en utilisant l'assemblage de pièces recyclées (spécificité de l'artiste portugais Bordalo II), la mosaïque, le grattage (picotagem en portugais, qui fait référence à la technique de creusement des affiches ou d'explosion au marteau piqueur de l'artiste portugais Vihls).

Illustration 9 - Techniques utilisées pour les fresques de la Galeria de Arte Urbana en 2014

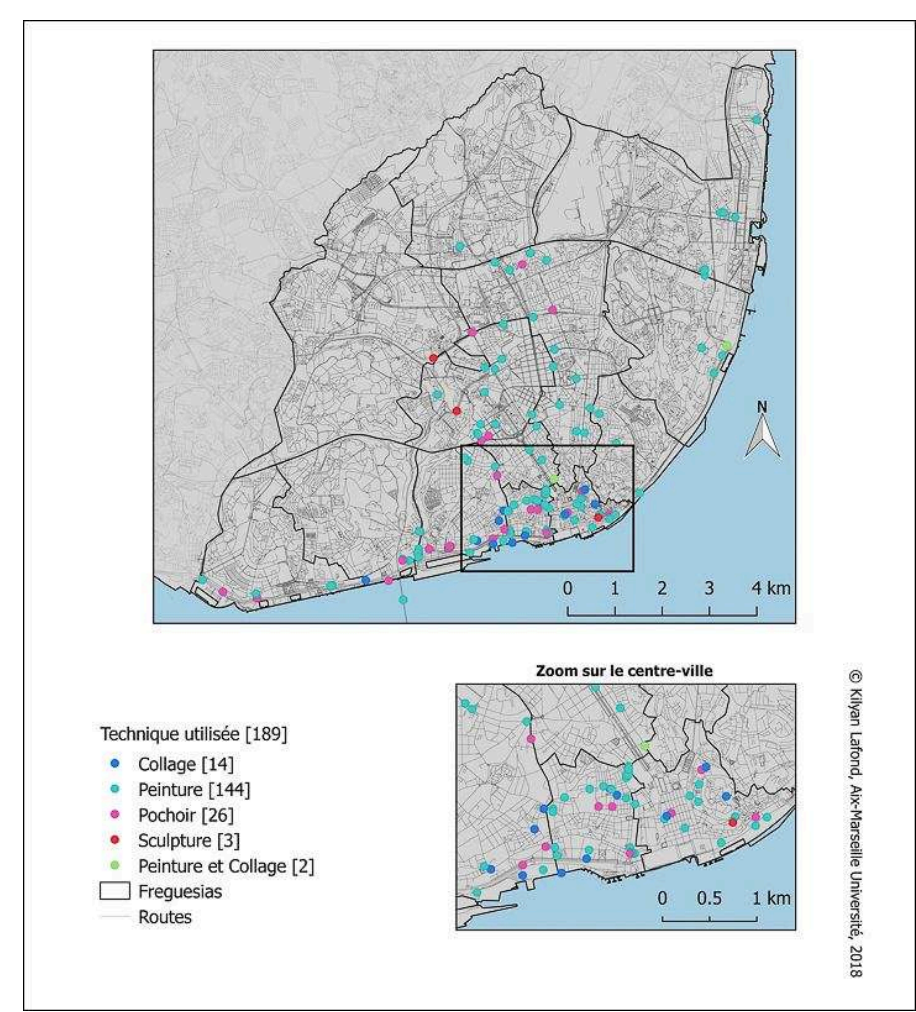




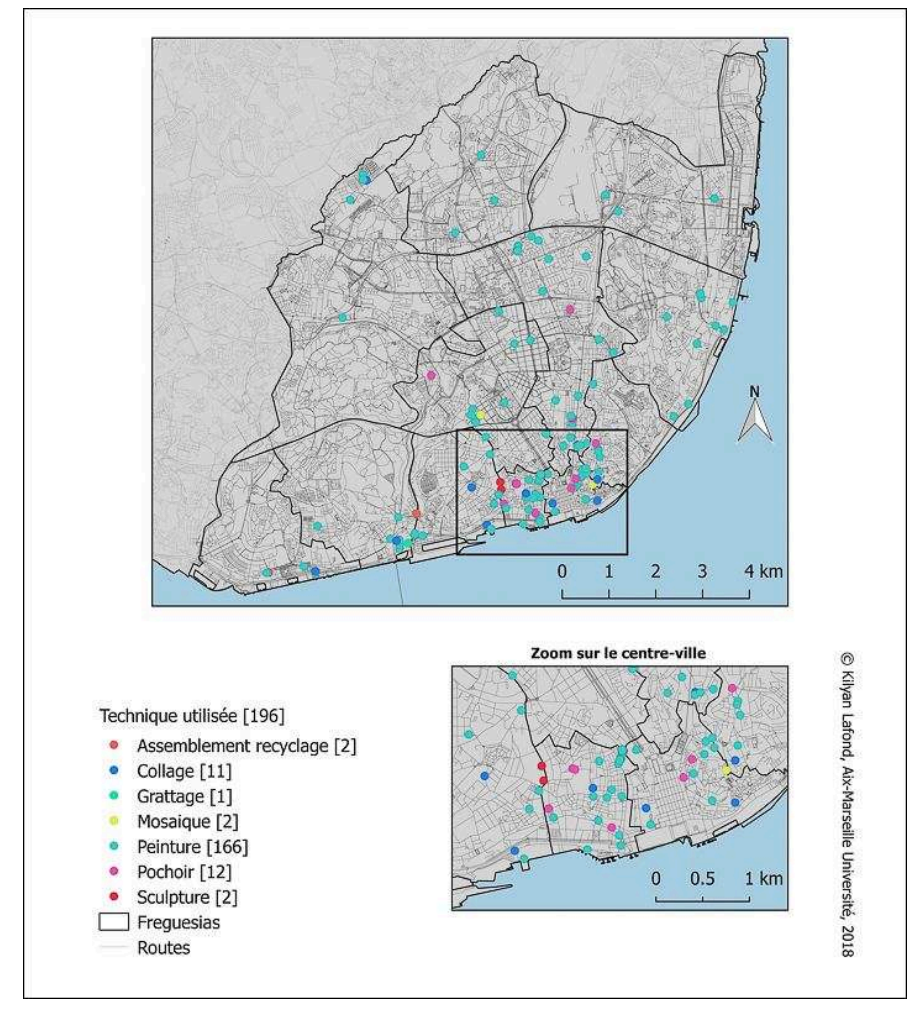

Afin de mieux identifier et comprendre l'implantation spatiale des fresques de la Galeria de Arte Urbana, nous avons ensuite superposé leur localisation à certaines données issues du dernier recensement portugais de 2011, afin de voir si une logique spatiale et/ou une logique socio-démographique était visible (http://censos.ine.pt) ${ }^{4}$. Sans perspective déterministe, nous souhaitions comparer les éléments de discours de la municipalité qui justifiaient la logique d'implantation des fresques, avec l'analyse du contexte social de ces implantations. Pour cela, nous avons sélectionné des indicateurs d'activités, de revenus et d'éducation. Les variables relatives au niveau de diplôme supérieur et à l'activité au sein du secteur tertiaire ont été sélectionnées car elles permettent de mettre en exergue les freguesias de Lisbonne où résident les populations les plus « créatives » (au sens de Florida, 2002). Nous avons souhaité comparer les lieux de résidence de ces créatifs avec l'implantation des fresques, afin de comprendre si l'implantation des œuvres pouvait favoriser la mise en place d'une ambiance spécifique aux activités créatives via l'esthétisation de la sous culture graffiti (Cabeçadas Do Carmo et al., 2014). La proportion d'individus analphabètes et le taux de chômage ont pour objectif, eux, de nous renseigner sur les inégalités socio-spatiales lisboètes, à l'échelle de la freguesia, afin de voir où se situent les populations les plus défavorisées (Galhardo, 2013 ; Observatório do QREN, 2013). La proportion d'hébergements collectifs permet d'avoir une proportion spatialisée de bâti destiné aux populations mobiles, de types individus en séjour d'affaires, touristes, et étudiants, qui sont le cœur de cible des populations que cherche à attirer Lisbonne (CML, 2015).

Les résultats de ces cartographies montrent que les fresques de la Galeria de Arte Urbana se concentrent au sein de freguesias où l'on observe un faible taux de chômage (entre $2,17 \%$ et $4,74 \%)^{5}$, une proportion quasi inexistante de personnes analphabètes, et où les actifs travaillent en majorité dans le secteur tertiaire (entre $37,4 \%$ et $41,9 \%$ ). 
Ces freguesias concentrent également le maximum de personnes détenant un diplôme du supérieur (entre $48,9 \%$ et $60,1 \%$ ), un capital économique notable, où les revenus perçus par les résidents lisboètes sont les plus hauts, où l'accès à la propriété et à la location est la plus importante, où les loyers sont les plus chers. Les graffitis de la Galeria de Arte Urbana apparaissent ainsi situés au sein de freguesias où le niveau de vie est élevé, et où les populations sont détentrices d'un capital culturel important. Ces chiffres viennent confirmer la volonté affichée par la mairie de faire émerger un cluster créatif, avec une atmosphère favorable, dans le centre historique.

Illustration 11 - Proportion de personnes au chômage et en recherche d'un nouvel emploi à Lisbonne en 2011 et géolocalisation des fresques de la Galeria de Arte Urbana

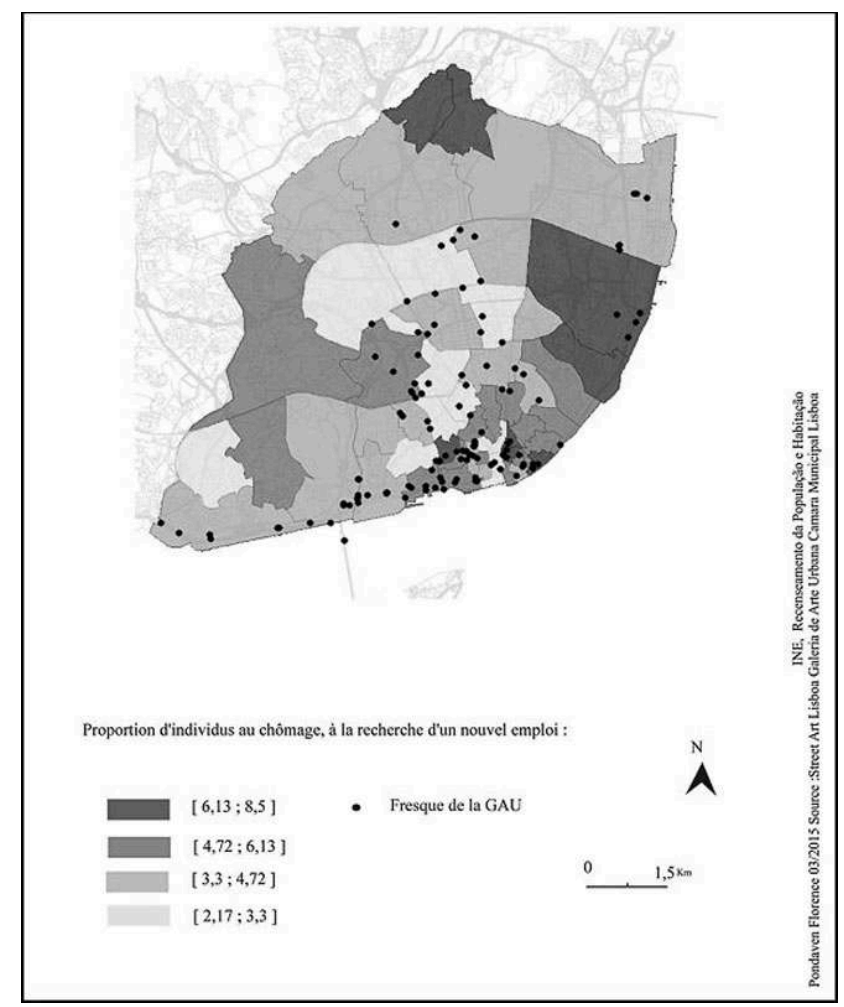


Illustration 12 - Proportion d'individus ayant un diplôme d'enseignement supérieur à Lisbonne en 2011 et géolocalisation des fresques de la Galeria de Arte

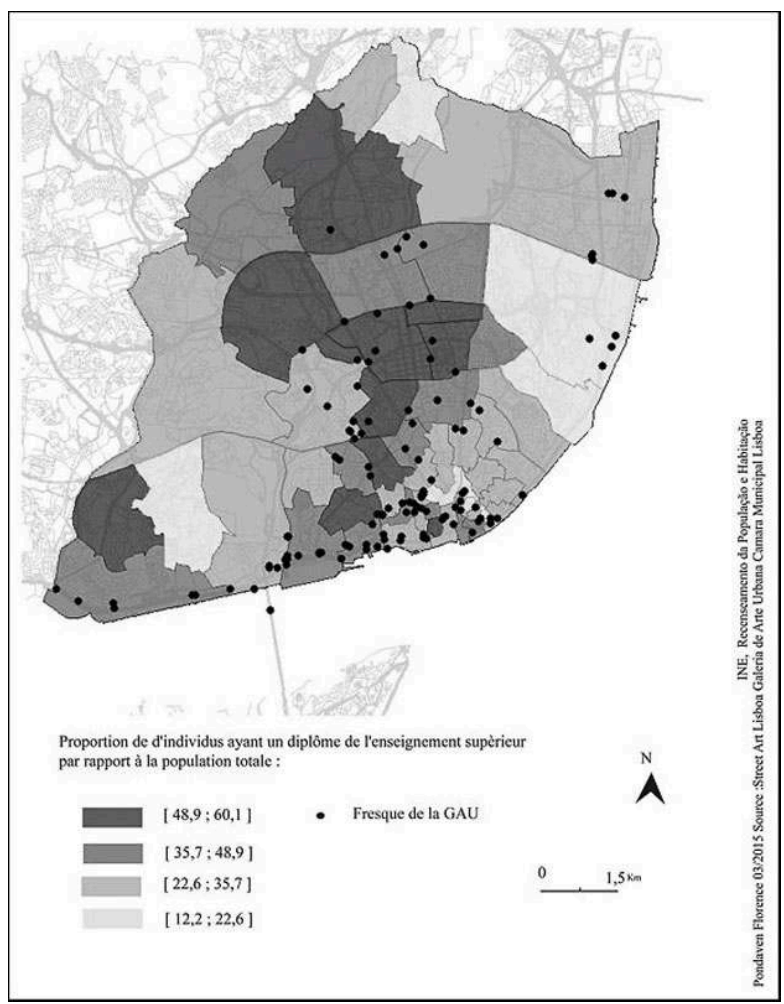

\section{Galeria de Arte Urbana, un outil de valorisation territoriale multiple et efficace dont les résultats sont discutés}

\section{La GAU, un outil de valorisation territoriale multiple...}

Nous avons vu que deux logiques spatiales marquaient la géographie du street art lisboète institutionnalisé. On a noté, d'abord, la volonté de créer de nouvelles polarités culturelles et créatives dans la ville. On les retrouve dans le centre historique lisboète, mais également en périphérie comme dans la freguesia du Parque das Nações, où se trouve la friche urbaine Braço de Prata (Pereira, 2017) et dans le quartier d'Alcantara, où une importante friche urbaine et les docks ont été réaménagés en faveur de l'économie créative et du tourisme (Giroud, 2007). On remarque dans la plupart des cas la volonté de mettre en place des projets permettant l'inclusion sociale et la création de lien social, en particulier dans les grands ensembles fonctionnels de la périphérie.

Dans la partie précédente de ce texte, nous avons observé que la localisation des fresques murales s'est pourtant d'abord réalisée dans le centre historique (illustrations 5, 7 et 9) pour se déplacer progressivement vers la périphérie (illustrations 6,8 et 10). Cette dynamique a différentes causes. La première est que depuis le début des années 1990 les artistes considéraient les rues du quartier Bairro Alto, réputées pour être le lieu de la fête et de la vie nocturne lisboète, comme leur terrain de jeu et d'expression privilégié. Vasco, un street artiste de la première heure, confirme : «Le Bairro Alto appartient aux personnes qui l'utilisent, qui le vivent. Il appartient aux 
artistes, à la communauté. (...) Pour les writers, ces murs sont à eux. Ils peignaient dans le Bairro Alto, avant même que la Galeria de Arte Urbana ne réalise ce qu'était le street art » (entretien semi-directif réalisé avec Rui, 25/05/15, Lisbonne). Le Bairro Alto fait partie du centre historique de la ville et il est à ce titre l'un des quartiers les plus fréquentés de Lisbonne. Il assurait donc aux artistes une visibilité maximale, mais cela allait à l'encontre des objectifs municipaux concernant la patrimonialisation urbaine du centre historique de Lisbonne comme l'explique la co-directrice de la Galeria de Arte Urbana: "Comme vous le savez au sein du centre-ville nous avons beaucoup de patrimoine culturel, le paysage est déjà « rempli » de points de repère. Ça ne paraît pas être le meilleur endroit pour apposer de nouvelles fresques de street art " (entretien semi-directif réalisé avec Inês Machado, 15/06/15, Lisbonne). C'est pour cette raison que les quartiers périphériques, et notamment les quartiers construits entre les années 1980 et 1990 sont désormais préférés par la municipalité pour y peindre. Ceux-ci ont été construits sur des zones industrielles, où les bidonvilles étaient une forme prépondérante de logement. Les quartiers de Marvila, Lumiar, Ameixoeira, Charneca, Benfica possèdent de grands ensembles d'habitation et les fresques ont essaimé dans ces zones afin de les embellir et d'entretenir une forme d'équilibre spatial de l'accès à l'art dans la ville. Ainsi, Inês Machado demande: "Pourquoi ne pas répandre ces interventions artistiques au sein de quartiers dont le paysage urbain n'est pas très beau, en améliorant un peu la qualité de vie dans ces quartiers? Maintenant, les habitants dans ces zones ont des œuvres d'art dans leurs quartiers, cela apporte une plus-value au territoire ».

Les fresques dans le centre-ville n'ont pour autant pas disparu mais elles sont de plus en plus encadrées par la municipalité qui favorise leur réalisation sur des supports mobiles ou sur des éléments de mobilier urbain afin de ne pas détériorer le patrimoine existant. Cette solution permet de conserver des œuvres alternatives, appréciées dans le centre historique autant par la population que par les touristes, tout en permettant de leur assurer un maximum de visibilité.

Les politiques favorisant le street art institutionnalisé sont également utilisées comme un outil permettant l'inclusion sociale ${ }^{6}$ des populations résidentes pauvres ou en situation de marginalité. Il est perçu, par les services municipaux, comme un outil favorisant la mise en place d'un vivre ensemble et de relations de proximité au sein de quartiers marqués par de graves difficultés sociales. Il permet de montrer aux populations en marge qu'elles ne sont pas oubliées par la municipalité. Ainsi, en mai 2015, le site Internet du journal national Publico, publico.pt, titrait à l'issue du festival MURO, organisé par la Galeria de Arte Urbana dans les quartiers Est de la métropole: "Des artistes nationaux et internationaux se regroupent dans trois quartiers pour leur donner vie à travers le graffiti. Jusqu'au 28 mai, graffeurs et habitants seront au festival MURO, les mains dans la peinture avec un même objectif: l'inclusion »(Serpa Pinto, 2017).

28 En plus de ces différents attributs de valorisation, la Galeria de Arte Urbana est considérée depuis sa création comme un outil important de promotion urbaine. Plusieurs visites guidées, à pied ou en minibus, ont été mises en place par des associations locales comme The real Lisbon street art tour ou par des opérateurs touristiques privés. La Galeria de Arte Urbana a également été intégrée aux stratégies de communication et de marketing urbain de la métropole portugaise, en particulier la stratégie de promotion « Marca Lisboa » (Camara Municipal de Lisboa, 2015). Celle-ci a 
permis d'affirmer l'identité de la capitale du Portugal autour du patrimoine et de la culture. Elle a été intégrée aux « Grandes options du plan 2015-2018 pour Lisbonne » et a permis à la métropole de remporter divers prix liés au tourisme: Mejor Destino de City Break en Europa (World Travel Awards) en 2013; Mejor Destino de Cruceros en Europa (World Travel Awards) en 2014. Dans cette optique de promotion territoriale, la Galeria de Arte Urbana est envisagée comme une infrastructure culturelle innovante, visant à valoriser l'espace public et attirer les touristes. Le street art lisboète et la Galeria de Arte Urbana sont ainsi considérés comme de véritables attractions intégrées à tous les documents officiels et touristiques grâce à un logo GAU. Ils sont valorisés par la mairie via la revue numérique Revista GAU (créée en 2008) et l'impression (en 2014 et 2016) de deux beaux livres qui présentent un recueil de photographies des fresques recensées à l'intérieur de la galerie. La Galeria de Arte Urbana possède un compte Facebook et un compte Instagram qui comptent respectivement près de 50000 et 8056 abonnés (janvier 2018). En 2015, la Galeria de Arte Urbana s'est également dotée d'un site internet où l'on retrouve les photographies des pièces de la galerie, accompagnées d'une carte interactive où elles sont référencées et où plusieurs promenades sont proposées. L'ensemble de ces éléments participe au rayonnement international de la Galeria de Arte Urbana.

Pour évaluer ce dernier, nous avons recensé puis sélectionné un corpus de cinquante articles provenant de grands médias internationaux à partir des occurrences obtenues dans le moteur de recherche Google sur les expressions "street art Lisbon ", "street art Lisbonne » et "street art Lisboa ». Après dix années d'existence, la Galeria de Arte Urbana est en passe de devenir une référence en matière de street art comme le confirme The Guardian à de multiples reprises (Dixon, 2011 ; Manco, 2011 ; Lorenz, 2015 ; Moore, 2017), le Huffington Post (Jaime \& Harrington, 2014; Van Poll, 2016) ou Télérama: «Politique osée, la municipalité soutient depuis 2008 l'explosion du street art, préférant accompagner, plutôt que réprimer, ces interventions sauvages. Une attitude intelligente et un pari réussi où chacun trouve son compte : les artistes, à qui des moyens sont donnés pour s'exprimer; la ville, qui les oriente vers des espaces et des lieux à réinvestir, en collaboration avec les services de l'urbanisme.» (BouruetAubertot, 2015). Les résultats positifs de cette promotion urbaine se retrouvent également au niveau national. Ainsi, le journal portugais publico.pt a publié, entre 2008 et 2017, vingt-neuf articles traitant de la Galeria de Arte Urbana. La totalité a été rédigée sous un angle positif, et met en avant la réussite du projet.

L'image de la GAU apparaît donc comme un important levier touristique, même si tous les visiteurs de Lisbonne ne sont pas informés de l'existence officielle de la galerie. Nous avons ainsi interrogé en 2015 de manière aléatoire cent trente-deux touristes afin d'appréhender leur perception de la Galeria de Arte Urbana. Seulement 6,8\% des touristes enquêtés connaissaient la Galeria de Arte Urbana, même si $50 \%$ estimaient que Lisbonne était une ville où l'on voyait beaucoup de graffitis ou quelques graffitis. Après présentation de la Galeria de Arte Urbana, 30 \% d'entre eux jugeaient qu'elle a un impact très positif sur la ville de Lisbonne et $20 \%$ d'entre eux estimaient que le projet a un impact positif. Seulement $13 \%$ des touristes enquêtés n'appréciaient pas l'impact des graffitis sur Lisbonne. 


\section{... avec certaines limites}

31 La valorisation territoriale et touristique par le street art institutionnalisé, aussi réussie soit-elle pour les pouvoirs publics, n'est pas exempte de toute critique. La première concerne l'institutionnalisation de la Galeria de Arte Urbana qui vide, pour certains activistes, le street art de son sens originel et de ses acteurs les plus subversifs pour le transformer en outil de décoration urbaine plutôt qu'en moyen d'expression des franges populaires contestataires. La direction de la Galeria de Arte Urbana se défend de cette vision. Elle affirme pourtant: «Nous savons que le graffiti provient de l'underground, c'est contre le système, c'est subversif. Nous n'essayons pas d'institutionnaliser le graffiti. Ce que nous essayons de faire, c'est de donner la possibilité à des gens intéressés par l'art de peindre sur différentes surfaces, de stimuler leur créativité » (entretien semi-directif réalisé avec Inês Machado le 15/06/15, Lisbonne). Le graffeur vandale Seb exprime la même idée, de manière différente : "Si la Galeria de Arte Urbana voit un mur qui est cool pour y faire quelque chose, ils nettoient tout, ils ne laissent aucun graffiti. [...] La Galeria de Arte Urbana, c'est comme si tu devais demander la permission pour tes idées, pour penser. Ils contrôlent tous les murs, si tu as une idée, tu dois attendre une réponse, ça c'est pas du graffiti. Le graffiti, c'est libre» (entretien semi-directif réalisé le 05/06/15, Lisbonne). Toutes les créations de street art lisboètes doivent être avalisées par la Galeria de Arte Urbana avant de s'inscrire sur un mur, ce qui exacerbe les tensions. Le conflit d'usage autour d'un des premiers lieux phares de la Galeria de Arte Urbana, le Bairro Alto, illustre bien la complexité des rapports entre les deux visions du street art. Les murs du quartier ont été repeints, et donc les graffitis vandales effacés, lors de son intégration dans le périmètre de la Galeria de Arte Urbana, ce qui a provoqué une réaction de colère des graffeurs locaux qui n'ont pas abdiqué malgré l'appropriation de "leurs » murs par la Galeria de Arte Urbana: "Je connais des vandales, qui ont 40-45 ans. Ils peignent dans le Bairro Alto depuis qu'ils ont 15 ans. (...) C'est à eux, c'est comme ça qu'ils le perçoivent. Et en nettoyant le Bairro Alto, ils offrent une nouvelle toile aux writers pour pratiquer » (entretien semi-directif réalisé avec Rui le 25/05/15, Lisbonne).

Ce rapport de force s'exprime également dans la sélection des street artistes par la Galeria de Arte Urbana qui exerce la fonction également de commissaire artistique. Un nombre important de graffeurs historiques venant de la culture hip-hop le dénonce : "La Galeria travaille avec un groupe de personnes dont elle sait que ce sont des professionnels qui ne viennent pas du mouvement hip-hop. Ils sont illustrateurs, designers, architectes... Elle travaille avec ces personnes et évacue le mouvement hiphop du street art" (entretien semi-directif réalisé avec Rui le 25/05/15, Lisbonne). L'étude du statut des street artistes recensés au sein de Galeria de Arte Urbana confirme cette idée. $64 \%$ d'entre eux travaillent en effet dans le secteur des activités créatives ${ }^{7}$. Ce sont des professionnels de l'art graphique, des designers, des infographistes, des artistes, des architectes ayant déjà des relations avec la municipalité dont la majorité des œuvres se situent dans l'hyper centre lisboète alors que les fresques réalisées par des personnes n'exerçant pas une activité professionnelle créative sont majoritairement situées hors du centre-ville. Ces dernières appartiennent au type de graffiti hip-hop.

Une des autres limites de la valorisation territoriale et touristique du street art est liée au mode de financement public/privé de la Galeria de Arte Urbana. Il est pratiqué 
depuis sa création et il a permis à la Galeria de Arte Urbana de se développer avec rapidité, d'autant que les financements privés sont en constante évolution. Actuellement, la Galeria de Arte Urbana est financée à hauteur de $80 \%$ par des multinationales sous la forme du mécénat culturel. Toyota, KLM, NOS, Auchan profitent en retour d'une exposition publicitaire, ainsi que d'une politique de défiscalisation. La direction de la Galeria de Arte Urbana confirme: "L'apparition de groupes et de marques, ayant de l'argent à dépenser dans de la publicité et des annonces, qui préféraient financer une fresque de street art plutôt que de réaliser un clip publicitaire pour la télévision, nous a permis de lutter contre la crise. Ces partenariats sont réalisés sans que les logos ne soient trop visibles. Ce sont des partenariats fréquents. Au début $80 \%$ de nos activités étaient soutenues et financées par le budget municipal. Aujourd'hui, c'est l'opposé, $20 \%$ de ce que nous faisons est fait avec le budget municipal, et le reste est réalisé avec l'argent de grands groupes ». Un accord est passé entre la Galeria de Arte Urbana et chaque mécène où ce dernier s'engage à la financer, à couvrir les frais logistiques nécessaire à la réalisation de la fresque et à payer les artistes. En échange, la Galeria de Arte Urbana demande à l'artiste de peindre le logo de la multinationale et lui assure ainsi une visibilité intégrée. La municipalité fait ensuite mention de ces financements dans ses communiqués et parutions Internet.

Cette situation est dénoncée par les opposants à la Galeria de Arte Urbana qui voit dans l'instrumentalisation du street art une suite logique à son institutionnalisation : «La GAU ne respecte pas du tout le graffiti. Il y a beaucoup de gens qui peignent avec leur propre argent, en risquant leur vie et en se battant contre la routine, c'est vraiment leur vie tu vois? Les gens qui peignent dans la rue, ils ne peignent pas pour l'argent, ils peignent par passion. (...) les artistes, les gens qui font réellement du graffiti, ils ne se laissent pas influencer par des grandes marques ou par la municipalité », précise Seb, un street artiste (entretien semi-directif réalisé le 05/06/15, Lisbonne). Sylvia Câmara, co-directrice de la Galeria de Arte Urbana est consciente de la suspicion engendrée par le financement de la Galeria de Arte Urbana: «Cette méfiance est renforcée par les modes de financement des projets de grande envergure qui mêlent initiatives privées et publiques. Dans le cadre de ces actions à grande échelle, la ville fournit souvent la logistique (échafaudages, signalétique, sécurité), tandis que les grandes marques, attirées par la visibilité hors pair ainsi offerte, financent les artistes. Si un contrôle rigoureux est mené pour éviter que l'opération ne tourne au panneau publicitaire grand format, le caractère commercial de ces démarches demeure " (Câmara, 2013). L'instrumentalisation mercantile du street art s'inscrit de ce point de vue dans le processus progressif mais constant de privatisation de la ville (Baraud-Serfaty, 2008) depuis le début des années 1980. Cette marchandisation, justifiée par la diminution des budgets publics et par le contexte de crise économique, se trouve en contradiction totale avec l'essence même du street art originel. Elle est pourtant devenue une réalité, corollaire des politiques publiques de valorisation territoriale et touristiques ainsi que des difficultés économiques qui touchent les collectivités locales.

\section{Conclusion}

L'institutionnalisation du street art à Lisbonne, matérialisée par la Galeria de Arte Urbana, est une initiative nouvelle et originale de requalification des espaces publics, d'inclusion sociale, de promotion urbaine et de mise en valeur d'un art jusqu'alors 
considéré comme vandale. Les fresques de la galerie s'inscrivent dans la logique du marketing urbain développé par la ville pour créer la «Marca Lisboa» et attirer les touristes et les « créatifs».

Les fresques de la Galeria de Arte Urbana sont ainsi implantées selon trois logiques spatiales corrélées aux projets de développement urbains lancés par la mairie depuis les années 2000 à la fois dans le centre historique de Lisbonne et dans les périphéries de la ville. La grande concentration des fresques dans le centre historique, ou à proximité de celui-ci, est liée aux politiques de régénération urbaine des quartiers anciens et à la volonté municipale de structurer un cluster créatif dans le quartier du Bairro Alto. Le street art institutionnalisé est ici utilisé pour créer un paysage urbain favorable aux activités créatives. Il occupe la même fonction dans les freguesias périphériques d'Alcantara et du Parque das Nações qui constituent les nouvelles polarités périphériques créatives de Lisbonne.

Les fresques de la Galeria de Arte Urbana suivent ainsi la cartographie des lieux dédiés au tourisme et à la créativité, en renforçant les identités urbaines des différents quartiers anciens du centre historique, et des quartiers créatifs de l'Est et de l'Ouest de Lisbonne. Le reste des fresques situées en périphérie dans des freguesias moins favorisées apparaît à la fois comme un outil de mise en valeur du bâti urbain de ces espaces en marge, et à la fois comme un levier culturel d'inclusion sociale des populations par l'accès à la culture.

Malgré ces impacts positifs importants du point de vue des promoteurs de la ville créative, la Galeria de Arte Urbana essuie un certain nombre de critiques. Son financement public-privé sous forme de mécénat des fresques et l'instrumentalisation de l'image de la culture underground pour en faire une ambiance urbaine attractive sont dénoncés par de nombreux acteurs historiques du mouvement street art vandale lisboète. L'institutionnalisation du street art à Lisbonne a divisé la scène street art locale entre les artistes qui collaborent avec la Galeria de Arte Urbana, même si certains conservent des pratiques illégales, et les artistes qui refusent d'y contribuer. L'institutionnalisation du street art crée ainsi une pratique artistique clivée : la première est tolérée, financée, intégrée à la politique municipale, promotionnée et, pour ses détracteurs, aseptisée; la seconde est illégale, underground, vandale mais n'a aucune finalité mercantile. Conscients de ces limites, mais satisfaits des résultats et faute d'autres moyens que le financement privé, les gestionnaires de la Galeria de Arte Urbana continuent de développer leurs fresques murales en misant sur l'image attractive et les retombées touristiques qu'elles génèrent

\section{BIBLIOGRAPHY}

Almeida D., Fumega J., Alves T., 2011. A noite como produto turístico a integrar no planeamento urbano. Finisterra-Revista Portuguesa de Geografia, n 92, p. 43-64. 
Austin J., 2001. Taking the train: How graffiti art became an urban crisis in New York City. Columbia University Press, New York, 400 p.

Bairrada E. M., Monteiro K., Cabral M., dos Santos A., 1985. Empedrados artísticos de Lisboa: A arte da Calçada-Mosaico. Lisboa, Ed. E.M. Bairrada, 602 p.

Baraud-Serfaty I., 2008. Capitales et capitaux. Le Débat, n 1, p. 96-105.

Baudrillard J., Lotringer S., 2005. Le complot de l'art. Paris, Sens et Tonka, 166 p.

Baudrillard J., et al., 1974. Kool Killer. Les graffiti de New York ou l'insurrection par les signes. Papers: revista de sociologia, $\mathrm{n}^{\circ}$ 3, p. 27-38.

Borghini S., Visconti L. M., Anderson L., Sherry J. F. Jr., 2010. Symbiotic postures of commercial advertising and street art. Journal of Advertising, 39(3), p. 113-126.

Bouruet-Aubertot V., 2015. Lisbonne, ça délire graff. Télérama. Consulté en janvier 2018. http:// www.telerama.fr/sortir/lisbonne-ca-delire-graff,121654.php

Burgel, G., 1999. Paris, avenir de la France. Editions de l'Aube. La Tour d'Aigues, 200 p.

Burgel G., Grondeau A., 2015. Géographie urbaine. Vanves, Hachette Éducation, 288 p.

Cabeçadas Do Carmo L., Pattaroni L., Pedrazzini Y., Piraud M.-S., 2014. Creativity Without Critique: an inquiry into the aesthetization of the alternative culture. In Lisbon Street: Art and Urban Creativity-2014 International Conference, p. 274-281, Urbancreativity.Org

Câmara S., 2013. Au Bairro Alto, un musée éphémère pour concilier arts urbains et patrimoine. In Masboungi A., Le projet urbain en temps de crise : l'exemple de Lisbonne. Paris, Le Moniteur, $160 \mathrm{p}$.

Camarinhas C., 2006. De l'avenue-promenade au" greenway". In Colloque international Cultures et médiation. Tours, Université François Rabelais-Tours, https://halshs.archives-ouvertes.fr/ halshs-00200447v2

Campos R., 2009. Entre as luzes e as sombras da cidade: visibilidade e invisibilidade no graffiti. Etnografica, vol. 13 (1), p. 145-170, https://doi.org/10.4000/etnografica.1292

Campos R., 2014. A luta voltou ao muro. Análise Social, n ${ }^{\circ} 49$, Lisboa, 212 p.

Carrancal M. A., 2009. Le développement culturel à Lisbonne : quel impact pour les politiques d'aménagement stratégique? Sud-Ouest européen. Revue géographique des Pyrénées et du Sud-Ouest, $n^{\circ} 27$, p. 39-52.

Castro A., Lucas J., Ferreira V. M. et al., 1997. O plano de urbanização da Expo'98 e os compromissos de política urbana de Lisboa. In Dossier: A Expo'98 em Lisboa. Lisboa, CIES-ISCTE/ CELTA, p. 123-142.

Chang J., 2007. Can't stop won't stop: A history of the hip-hop generation. New York, St. Martin's Press, $564 \mathrm{p}$.

Cinti T., 2008. Cultural clusters and districts: the state of the art. Creative cities, cultural clusters and local economic development, p. 70-92.

CML, 1992. Plano Estrategico de Lisboa. Direcçao de Planeamento Estrategico.

CML, 2005. Visão Estratégica 2012.

CML, 2013. Lisboa economia criativa (Blueprint). https://issuu.com/camara_municipal_lisboa/docs/ lisboa_economia_criativa

CML, 2015. Grandes opções do plano para a cidade de Lisboa. Câmara Municipal de Lisboa. 129 p., http://www.am-lisboa.pt/451500/1/001446,000265/index.htm 
Costa, P. (2007). A cultura em Lisboa: competitividade e desenvolvimento territorial. Lisboa, Imprensa de ciências sociais, 475 p.

Costa P., 2013. Bairro Alto revisited: reputation and symbolic assets as drivers for sustainable innovation in the city. DINÂMIA'CET-IUL, https://doi.org/10.7749/dinamiacet-iul.wp.2013.14

Costa P., Lopes, R., 2015. Urban design, public space and the dynamics of creative milieux: a photographic approach to Bairro Alto (Lisbon), Gràcia (Barcelona) and Vila Madalena (São Paulo). Journal of Urban Design, 20(1), p. 28-51.

Cousin S., 2008. L'Unesco et la doctrine du tourisme culturel. Civilisations, 57(1), p. 41-56.

Cruzeiro M. M., 2004. O imaginário político do 25 de Abril. Rivista di studi portoghesi e brasiliani, $6(6)$, p. $1000-1008$.

da Costa Xavier A. J. T., de Almeida A. S. A., 2017. Políticas locais e impactos na conceção da experiência turística em espaços urbanos-os casos do bairro alto e da mouraria, lisboa. Revista Brasileira de Gestão e Desenvolvimento Regional, p. 322-350.

DCMS U., 1998. Consulting, Mapping the creative industries: a toolkit. British Council's Creative And Cultural Economy Series. London, British Council, 62 p. https://creativeconomy.britishcouncil.org/ media/uploads/files/English_mapping_the_creative_industries_a_toolkit_2-2.pdf

de Araújo N., de Jesus Martins J., 1938. Peregrinações em Lisboa. Lisboa, Parceria AM Pereira, Vol. 2.

Di Nardo L., Cortese V., McAnaney D., 2010. Le fonds social européen et l'inclusion sociale. Union Européenne, http://ec.europa.eu/employment_social/esf/docs/sf_social_inclusion_fr.pdf

Dickens L., 2010. Pictures on walls? Producing, pricing and collecting the street art screen print. City, 14 (1-2), p. 63-81.

Dickinson M., 2008. The Making of Space, Race and Place: New York City's War on Graffiti, 1970the Present. Critique of Anthropology, 28(1), p. 27-45.

Dixon R., 2011. Urban splash: street art in Lisbon. The guardian. https://www.theguardian.com/ travel/2011/jan/29/graffiti-street-art-lisbon-portugal

Dourado Sequeira, A., 2015. The street as canvas and the construction of artistic carreers. In Guerra P. et Moreira T. (ed.), Keep it Simple, Make it Fast! An approach to underground music scenes. Universidade do Porto, Faculdade de letras, p. 38-48.

Droney D., 2010. The business of "Getting Up": Street art and marketing in Los Angeles. Visual Anthropology, 23(2), p. 98-114.

Ferreira C., 2010. Cultura e regeneração urbana: novas e velhas agendas da política cultural para as cidades. Revista Tomo, 16, p. 29-56.

Ferrell J., 1993. Crimes of style: Urban graffiti and the politics of criminality. New York, Garland, vol. 3, $\mathrm{n}^{\circ} 4$, p. 98-101.

Ferrell J., 2016. Graffiti, street art and the politics of complexity. Routledge Handbook of Graffiti and Street Art, $520 \mathrm{p}$.

Florida R., 2002. The rise of the creative class. The Washington Monthly, 34(5), p. 15-25.

Fortuna C., Peixoto P., 2005. Politiques patrimoniales et réhabilitation urbaine au Portugal. Pôle sud, (1), p. 127-141.

Fraenkel B., 2007. Actes d'écriture: quand écrire c'est faire. Langage et société, nº 3, p. 101-112. 
Gabriel L., Estevens A., André I., 2013. Street Art: contested spaces and contestation through (Public) Spaces. Communication au IV EUGEO Congress, Europe, what's next, 5-7/09/2013, Rome, 13 p, http://www.eugeo2013.com/extended-abstracts/144-gabriel-l-estevens-a-andre-i-streetart-contested-spaces-and-contestation-through-public-spaces

Gaeiras B., 2017. FabLab Lisboa: when a Municipality Fosters Grassroots, Technological and Collaborative Innovation. Field Actions Science Reports. The journal of field actions, Special Issue 16, p. 30-35.

Galhardo J., 2013. Ville et mondialisation : le centre ancien de Lisbonne. Le Globe. Revue genevoise de géographie, 153(1), p. 23-38, https://doi.org/10.3406/globe.2013.6497

Galhardo, J., 2014. As desigualdades fontes de dinâmicas urbanas no centro histórico de Lisboa. Cadernos Metrópole, 16(32), p. 513-536, https://doi.org/10.1590/2236-9996.2014-3210

Genin C., 2013. Le street art au tournant: reconnaissances d'un genre. Bruxelles, Les impressions nouvelles, $272 \mathrm{p}$.

Genin C., 2015. Le street art : de nouveaux principes? Cahiers de Narratologie. Analyse et théorie narratives, $\mathrm{n}^{\circ} 29$, p. 15.

Ghorra-Gobin C., 2009. L'architecte, la façade et le piéton. Le Débat, n 3, p. 170-174.

Ginhoux B., 2015. En dehors du stade: l'inscription des supporters «ultras» dans l'espace urbain. Métropolitiques. 12 p., http://www.metropolitiques.eu/En-dehors-du-stade-l-inscription.html Giroud M., 2007. Résister en habitant ? Renouvellement urbain et continuités populaires en centre ancien (Berriat Saint-Bruno à Grenoble et Alcântara à Lisbonne). Thèse de doctorat, Université de Poitiers, $528 \mathrm{p}$.

Gravereau S., 2012. Lx Factory dans le quartier d'Alcantara à Lisbonne : un ilot artistique dans un territoire en pleine transformation. In Lucchini F. (dir.), De la friche industrielle au lieu culturel.), Atelier 231 - Centre National des Arts de la Rue - Université de Rouen, p. 67-74, https:// s3.amazonaws.com/academia.edu.documents/32892827/

livretcolloquelafricheseptembre2012_1350630402717.pdf?

AWSAccessKeyId=AKIAIWOWYYGZ2Y53UL3A\&Expires=1524049749\&Signature=g\%2BODCjij69goEIsRGec14sRGEsQ\%3D\&responsecontent-

disposition=inline\%3B\%20filename\%3D25._processus_et_actions_patrimoniales_d.pdf\#page=67

Guinard P., 2010. Quand l'art public (dé) fait la ville ? La politique d'art public à Johannesburg. EchoGéo [En ligne], 13 | 2010, mis en ligne le 20 septembre 2010, http://journals.openedition.org/ echogeo/11855; DOI : 10.4000/echogeo.11855

Halsey M., Pederick B., 2010. The game of fame: mural, graffiti, erasure. City, 14(1-2), p. 82-98.

Halsey M., Young A., 2006. 'Our desires are ungovernable' Writing graffiti in urban space. Theoretical criminology, 10(3), p. 275-306.

Heinich N., Shapiro R., 2012. De l'artification : enquêtes sur le passage à l'art. Paris, Editions de l'Ecole des Hautes Etudes en Sciences Sociales, 488 p.

Holton K. D., 1998. Dressing for Success: Lisbon as European Cultural Capital. Journal of American folklore, p. 173-196.

Irvine M., 2012. The work on the street: Street art and visual culture. The handbook of visual culture, p. 235-278. 
Jaime R., Harrington S., 2014. Exploring Lisbon As A Street Art Tourist. Huffington Post. Consulté sur : https://www.huffingtonpost.com/jaime-rojo-steven-harrington/lisbon-streetart_b_5611789.html

Keizer K., Lindenberg, S., Steg, L., 2008. The spreading of disorder. Science, 322(5908), p. $1681-1685$.

Landes O., 2015. Street art et projet urbain, une mise en valeur croisée dans la ville en transition. Cahiers de Narratologie. Analyse et théorie narratives, $n^{\circ} 29$, p. 9.

Lopes F., Catarino J., 2013. Régénérer le cœur historique : l'exemple de la Baixa Pombalina. In Masboungi A., Le projet urbain en temps de crise: l'exemple de Lisbonne. Le Moniteur. p. 96-101.

Lorenz T., 2015. Meet the 'graffiti grannies' of Lisbon. The Guardian. Consulté sur : https:// www.theguardian.com/artanddesign/shortcuts/2015/sep/13/the-graffiti-grannies-of-lisbon

Manco T., 2011. The 10 best street art works - in pictures. The Guardian. Consulté sur : https:// www.theguardian.com/culture/gallery/2011/aug/07/art

Marques L., 2017. Creative Clusters in Urban Spaces. London, The Sage Handbook of New Urban Studies, $343 \mathrm{p}$.

McAuliffe C., 2012. Graffiti or street art? Negotiating the moral geographies of the creative city. Journal of urban affairs, 34(2), p. 189-206.

McAuliffe C., Iveson, K., 2011. Art and crime (and other things besides...): Conceptualising graffiti in the city. Geography Compass, 5(3), p. 128-143.

Menezes M., 2011. Todos na Mouraria? Diversidades, desigualdades e diferenças entre os que vêm ver o bairro, nele vivem e nele querem viver. XI congresso luso-afro-brasileiros de ciências sociais. Diversidades e (des) Igualdades, p. 7-10.

Moore M., 2010. Intro. In Underdogs. Lisboa,Vera Cortês Agência de Arte, p. 4-17.

Moore M., Cruz L., 2007. Visual Street Performance 2007. Lisboa, Tipografia Peres.

Moore R., 2017. How down-at-heel Lisbon became the new capital of cool. The Guardian. Consulté sur : https://www.theguardian.com/artanddesign/2017/apr/16/lisbon-new-capital-of-coolurban-revival-socialist-government-poor-antonio-costa

Morovich B., 2014. Entre stigmates et mémoires: dynamiques paradoxales de la rénovation urbaine. Articulo-Journal of Urban Research, Special issue 5, 12 p., https://journals.openedition.org/ articulo/2529

Neves P. S., 2011. Plataforma de arte urbana, prenúncio de uma mudança em Lisboa. In Actas da Conferência Arte \& Sociedade, Lisboa, CIEBA/FBAUL, p. 247-255.

Observatório do QREN., 2013. Contributo das intervenções do QREN para a inclusão social de indivíduos residentes em territórios urbanos problemáficos. Lisboa, Secretaria General do Ministério das Finanças. 89 p., http://www.observatorio.pt/destaque.php?lang=0\&id_page=765

Pavel F., 2016. El Bairro Alto en liboa entre gentrificacion, turistificacion y derechos de la poblacion. Congreso Internacional Contested Cities, Madrid, $12 \mathrm{p}$.

Penn R., 2005. Cathedrals of Sport: football stadia in contemporary England. Soccer Review, $\mathrm{n}^{\circ} 4$, p. 27-30.

Pereira P., 2017. La transformación de la ribera oriental de Lisboa: un caso de gentrificación por nueva construcción. Revista EURE-Revista de Estudios Urbano Regionales, p. 47-71. 
publico.pt., 2008. Lisboa: Primeira galeria de arte urbana pretende ser espaço para graffitis. Consulté sur : https://www.publico.pt/2008/10/17/culturaipsilon/noticia/lisboa-primeira-galeria-dearte-urbana-pretende-ser-espaco-para-graffitis-1346496

Rosa L., 1999. O Plano de urbanização da zona de intervenção da Expo 98. A cidade da Expo, n 98 , p. 173-183.

Rousseau M., 2008. «Bringing politics back in»: la gentrification comme politique de développement urbain? Espaces et sociétés, $\mathrm{n}^{\circ}$ 1, p. 75-90.

Saisana M., Montalto V., Jorge Tacao Moura C., Langedijk S., 2017. The Cultural and Creative Cities Monitor. Consulté sur : https://composite-indicators.jrc.ec.europa.eu/cultural-creative-citiesmonitor

Saldanha A., 2013. Experiência Estética e Simbólica do Muralismo Português em Período Revolucionário. Revista e-scrita: Revista do Curso de Letras da UNIABEU, 4(4), p. 297-317.

Santana F., Sucena E., 1994. Dicionário da história de Lisboa. C. Quintas e Associados. Sacavém, 991 p. Serpa Pinto N., 2017. Marvila inunda 15 paredes de arte para derrubar muros. publico.pt. Consulté sur : https://www.publico.pt/2017/05/25/local/noticia/inclusao-social-estampada-em-15-paredes-demarvila-1773421

Simões M. C., 2014. Graffiti e street art em Portugal. Tese de Mestrado em Arte, Patrimonio, e a Teoria do Restauro, Universidade de Lisboa, Faculdade de Letras.

Thompson K., Offler N., Hirsch L., Every D., Thomas M. J., Dawson, D., 2012. From broken windows to a renovated research agenda: A review of the literature on vandalism and graffiti in the rail industry. Transportation research part A: policy and practice, 46(8), p. 1280-1290.

Union Européenne, 2007. Traité de Lisbonne.

Van Poll B., 2016. Cities Embracing Street Art for City Branding. Huffington Post. Consulté sur : https://www.huffingtonpost.com/bart-van-poll/cities-embracing-street-a_b_10053996.html Wilson J. Q., Kelling G. L., 1982. Broken windows. Atlantic monthly, 249(3), p. 29-38.

Yazigi E., 1996. Breve histórico sobre a arte de calcetaria em Portugal e no Brasil: o caso do mosaico português. Paisagem e Ambiente, (9), p. 99-123.

Young A., 2010. Negotiated consent or zero tolerance? Responding to graffiti and street art in Melbourne. City, 14(1-2), p. 99-114.

\section{NOTES}

1. Le centre historique de Lisbonne est représenté par la freguesia «Santa Maria Maior » créée en 2012 dans un contexte de rationalisation de l'organisation administrative de Lisbonne; le nombre de freguesia de la ville, l'échelon administratif le plus petit du Portugal, diminue de moitié (53 freguesia, à 24 en 1999). Le centre historique est créé à partir de la fusion de 12 freguesias les plus anciennes de la ville, qui rassemblent les 4 quartiers anciens : Bairro Alto, Baixa Chiado Alfama et Mouraria (CML, 2012 ; Galhardo, 2014).

2. http://observatorio-das-desigualdades.cies.iscte.pt/index.jsp?page=projects\&id=119

3. https://www.ine.pt, «Edifícios (n⿳o) por localização geográfica (à data dos Censos 2011), Época de construção e Estado de conservação ; Decenal ». 
4. Les variables choisies sont issues du recensement portugais de 2011 par l'Institut National Statistique portugais (INE). Ces cartes sont réalisées à l'échelle de la freguesia, qui est l'échelon d'intervention adopté par la Galerie d'art urbain.

5. Les pourcentages donnés sont des intervalles de valeur, pour une discrimination en plage de couleur. Il convient de lire « Un taux de chômage compris entre 2,17 \% et 4,74 \% de chômage dans la population étudiée ".

6. L'inclusion sociale est entendue ici « comme un processus permettant aux personnes exposées au risque de pauvreté et d'exclusion sociale de disposer des possibilités et des ressources nécessaires pour participer activement à la vie économique, sociale et culturelle et de parvenir à un niveau de vie et de bien-être qui soit considéré comme normal dans la société dans laquelle elles vivent. L'inclusion sociale permet aussi aux groupes et aux personnes vulnérables, d'une part, de participer davantage aux processus décisionnels qui affectent leur existence et, d'autre part, de pouvoir exercer leurs droits fondamentaux. »(Di Nardo, Cortese, \& McAnaney, 2010)

7. «Les activités ayant pour origine la créativité individuelle, les compétences, et le talent ayant le potentiel de créer de la richesse et des emplois, grâce à la génération et à l'exploitation de la propriété intellectuelle » (DCMS, 1998).

\section{ABSTRACTS}

The lisboet's Galeria de Arte Urbana is a regional planning operation which consists in institutionalizing the practice of street art in the capital city of Portugal for territorial and touristic valorization purposes. This paper aims at showing how this operation was carried out alongside public policies in favor of culture and creativity, as well as and gentrification of the city's historic center. We will study the functioning of the GAU, its organization, and its goals and will show how GAU modifies the evolution the local street art geography. We will analyze the territorial impacts of street art's institutionalization from social and economic points of view but also as regards urban marketing. Then we will question the limits for this operation and its criticisms notably as concerns the selection of works and authorized artists as well as private funding.

La Galeria de Arte Urbana lisboète est une opération d'aménagement du territoire consistant à institutionnaliser la pratique du street art dans la capitale du Portugal à des fins de valorisations territoriales et touristiques. Nous verrons dans cet article comment cette opération a été mise en place en parallèle des politiques publiques en faveur de la culture, de la créativité et de la gentrification d'une partie du centre historique lisboète. Nous étudierons le fonctionnement de la GAU, son organisation et ses objectifs et montrerons comment elle a participé à l'évolution de la géographie $\mathrm{du}$ street art local. Nous analyserons les impacts territoriaux de l'institutionnalisation du street art en termes économique et social mais également en matière de marketing urbain, puis nous mettrons en perspective les limites de cette opération et les critiques qu'elle subit notamment en matière de sélection des œuvres, des artistes autorisés à peindre au sein de la GAU et de financement privé. 
INDEX

Keywords: street art, Lisboa, creative city, public policy, urban marketing

Mots-clés: street art, Lisbonne, ville créative, politique publique, marketing urbain

\section{AUTHORS}

\section{ALEXANDRE GRONDEAU}

Alexandre Grondeau, alexandre.grondeau@univ-amu.fr, est maître de conférences à l'Université d'Aix-Marseille et membre de l'UMR 7303, Laboratoire TELEMMe. Il a publié récemment :

- Grondeau A., 2017. Sophia-Antipolis entre crises et résilience : un système productif dédié à l'innovation et son territoire à l'épreuve du temps. Sud-Ouest européen, $\mathrm{n}^{\circ} 41-42$, Les mutations des systèmes productifs : regards croisés France-Espagne.

- Grondeau A., Burgel G., 2015. Géographie Urbaine. Hachette Supérieur, 288 p.

\section{FLORENCE PONDAVEN}

Florence Pondaven est doctorante à l'UMR 8562, Centre Norbert Elias, Université d'Avignon et Pays du Vaucluse. 